\title{
Regulation of gene expression in Vibrio cholerae by ToxT involves both antirepression and RNA polymerase stimulation
}

Rosa R. Yu ${ }^{1 \dagger}$ and Victor J. DiRita ${ }^{1,2 *}$

${ }^{1}$ Department of Microbiology and Immunology and ${ }^{2}$ Unit for Laboratory Animal Medicine, University of Michigan Medical School, Ann Arbor, MI 48109, USA.

\section{Summary}

Co-ordinate expression of many virulence genes in the human pathogen Vibrio cholerae is under the direct control of the ToxT protein, including genes whose products are required for the biogenesis of the toxin-co-regulated pilus (TCP) and cholera toxin (CTX). This work examined interactions between ToxT and the promoters of $c t x$ and tcpA genes. We found that a minimum of three direct repeats of the sequence TTTTGAT is required for ToxT-dependent activation of the ctx promoter, and that the region from -85 to -41 of the tcpA promoter contains elements that are responsive to ToxT-dependent activation. The role of H-NS in transcription of ctx and tcpA was also analysed. The level of activation of $c t x-l a c Z$ in an E. coli hns strain was greatly increased even in the absence of ToxT, and was further enhanced in the presence of ToxT. In contrast, H-NS plays a lesser role in the regulation of the tcpA promoter. Electrophoretic mobility shift assays demonstrated that 6x His-tagged ToxT directly, and specifically, interacts with both the ctx and tcpA promoters. DNase I footprinting analysis suggests that there may be two ToxT binding sites with different affinity in the ctx promoter and that ToxT binds to -84 to -41 of the tcpA promoter. In vitro transcription experiments demonstrated that ToxT alone is able to activate transcription from both promoters. We hypothesize that under conditions appropriate for ToxT-dependent gene expression, ToxT binds to AT-rich promoters that may have a specific secondary conformation, displaces H-NS and stimulates RNA polymerase resulting in transcription activation.

\footnotetext{
Accepted 24 September, 2001. *For correspondence. E-mail vdirita @ umich.edu; Tel. (+1) 734936 3804; Fax (+1) 734764 3562. 'Present address: Department of Biochemistry, Stanford University School of Medicine, Beckman B-400, 279 West Campus Drive, Stanford, CA 94305-5307, USA.
}

Introduction

Vibrio cholerae is a Gram-negative bacterium which causes the watery diarrhoeal disease cholera. It is acquired by oral ingestion of the bacterium with contaminated food or water (Finkelstein, 1973). The organism colonizes the human small intestine in which it produces several virulence factors that cause the disease. The major virulence factors for $V$. cholerae are cholera toxin (CTX) and the toxin-co-regulated pilus (TCP), which are expressed in response to specific environmental conditions such as temperature, $\mathrm{pH}$ or osmolarity (Gardel and Mekalanos, 1994; Miller and Mekalanos, 1988). CTX is the best-characterized virulence factor and is composed of a single A subunit and five identical B subunits (Gill, 1976; Pearson and Mekalanos, 1982). The enzymatically active $A$ subunit is predominantly responsible for fluid loss through an ADP-ribosylation mechanism that results in constitutive cyclic-AMP (cAMP) production in host cells, leading to the opening of normally gated ion channels in the membrane (Betley, Miller and Mekalanos, 1986). Environmental signals optimal for CTX production also stimulate the expression of TCP (Peterson and Mekalanos, 1988; Taylor et al., 1987). TCP is a pilus in the type IV family that is essential for colonization and virulence. It is made up of a single pilin encoded by the tcpA gene, which is part of the $V$. cholerae pathogenicity island (VPI) that includes other $t c p$ genes whose products are involved in the biogenesis of the pilus structure, as well as the toxT gene (Peterson and Mekalanos, 1988; Kaufman et al., 1993; Ogierman et al., 1993; Karaolis et al., 1998).

Co-ordinate expression of CTX and TCP is the result of the action of several regulatory proteins. In the current model, these proteins function in a regulatory cascade in which ToxR and TcpP, two inner membrane proteins, are required for activation of tox $T$ transcription, and ToxT activates expression of $c t x$ and tcpA- $F$ directly (DiRita et al., 1991; Brown and Taylor, 1995; Skorupski and Taylor, 1997; Häse and Mekalanos, 1998; Yu and DiRita, 1999). tox $T$ resides downstream of $t c p F$ within the TCP gene cluster in the VPI and its transcription is autoregulated: activation of toxT by ToxR and TcpP is required to prime an autoregulatory loop in which ToxT-dependent transcription of the tcpA promoter reads through a proposed terminator between the tcpF and tox $T$ genes, resulting in 
continued ToxT production (Brown and Taylor, 1995; Yu and DiRita, 1999).

ToxT is a $32 \mathrm{kDa}$ cytoplasmic protein in the AraC family of transcriptional activators (Higgins et al., 1992). It has two conserved helix-turn-helix motifs at its carboxyl terminus that are the proposed DNA-binding domains and are common with other members in the family (Higgins et al., 1992; Gallegos et al., 1997). There is no conserved motif at the amino terminus between the members but, for some of them, the N-terminal domain is responsible for oligomerization and/or effector binding (Gallegos et al., 1997). For example, for AraC, the regulator of the L-arabinose operon encoding genes in $E$. coli that are involved in arabinose transport and catabolism, the $\mathrm{N}$-terminus is involved in both dimerization and arabinose binding. For UreR, the activator for urease gene expression in a number of species within the family Enterobacteriaceae, the $\mathrm{N}$ terminus is probably involved in binding of the effector molecule urea (Gallegos et al., 1997; Thomas and Collins, 1999). For ToxT, the function of the N-terminus is unclear, but it is probably involved in oligomerization and may also be the binding domain of a potential negative modulator, bile (Gupta and Chowdhury, 1997; Schuhmacher and Klose, 1999).

ToxT is the direct activator of several important virulence factors. Therefore, complete understanding of pathogenicity in $V$. cholerae requires thorough analysis of its function as a global regulator. The paradigm for studying bacterial transcription activation is the $E$. coli catabolite activator protein (CAP), also known as the cAMP receptor protein (CRP) (Kolb et al., 1993; Busby and Ebright, 1999). CAP protein functions as a homodimer to stimulate transcription in the presence of the allosteric effector cAMP. Simple CAP-dependent promoters can be divided into two classes (Ebright, 1993; Busby and Ebright, 1997). In class I CAP-dependent promoters, the CAP binding site is located upstream of the RNA polymerase (RNAP) binding site, and transcription activation involves interactions between CAP and the RNAP $\alpha$ subunit C-terminal domain $(\alpha-C T D)$ that facilitate binding of RNAP to promoter DNA to form the RNAP-promoter closed complex. In class II CAP-dependent promoters, the CAP binding site overlaps the -35 region of the promoter, and transcription activation involves two types of interactions between CAP and RNAP: one is with the $\alpha$-CTD and facilitates RNAP-promoter closed complex formation and the other is with the $\alpha$ subunit N-terminal domain ( $\alpha-N T D)$, and facilitates isomerization of the RNAP-promoter closed complex to the open complex (Busby and Ebright, 1999). Although biochemical data on transcription activation by the AraC family are scarce, mechanisms used by CAP for transcription activation can be generalized to these AraC family members as well (Reeder and Schleif, 1993; Jair et al., 1995; 1996a; 1996b; Kaldalu et al., 1996). A major constraint in the study of AraC family proteins has been the difficulty of handling them, as most of them are highly insoluble and thus difficult to purify. Therefore, studying ToxT and the promoters it controls can also provide insights into the function of AraC transcriptional activators.

There is no sequence homology between the ctx and tcpA promoters, beyond the fact that they are both AT-rich. Stretches of AT tracts have been shown to cause intrinsic curvature in DNA (Diekmann, 1986; Koo et al., 1986), and intrinsic bends near promoter regions may facilitate binding of RNAP (Pérez-Martín, et al., 1994). Some transcriptional activators can induce further bending of the promoters that may enhance recruitment of or interaction with RNAP. Examples include the CAP protein, and also two AraC homologues, MarA and SoxS (Schultz et al., 1991; Jair et al., 1996a; Parkinson et al., 1996; Rhee et al., 1998).

$\mathrm{H}-\mathrm{NS}$, a histone-like, nucleoid structuring protein, binds DNA in a relatively sequence-independent manner but prefers intrinsically curved, AT-rich sequences. Nye and colleagues demonstrated recently that $\mathrm{H}-\mathrm{NS}$ silences virulence gene expression at multiple levels in the ToxR regulatory cascade in $V$. cholerae (Nye et al., 2000), a finding consistent with the AT-rich nature of the ctx and tcpA promoters. H-NS is a major component of the bacterial nucleoid involved in condensing and packaging DNA and modulating gene expression. It also acts as a global regulator of expression of environmentally controlled genes in many Gram-negative bacteria, mostly in a negative manner, by modulating levels of negative DNA super-coiling required for transcription, or functioning as a transcriptional repressor to interfere with the formation of RNAP-promoter open complexes (Atlung and Ingmer, 1997; Williams and Rimsky, 1997). Nye and colleagues showed that an hns mutation derepressed expression of tox $T$, ctx, and $t c p A$ under several environmental conditions, even in the absence of their cognate activator proteins (Nye et al., 2000). H-NS has also been shown to play a negative role in regulating several promoters that are positively regulated by AraC family members, such as VirF of Shigella flexneri, UreR of Proteus mirabilis, CfaD, Rns and AppY of E. coli (Jordi et al., 1992; Tobe et al., 1993; Atlung et al., 1996; Murphree et al., 1997; Coker et al., 2000). Therefore, a general feature of AraC family members may be their ability to counteract the negative effect imposed by H-NS.

In this study, we examined interactions between ToxT, the promoters of $c t x$ and $t c p A$ genes, and $\mathrm{H}-\mathrm{NS}$, with the goal of defining promoter requirements and DNA recognition sites for ToxT activation and, ultimately, the mechanism by which ToxT activates transcription. We show that ToxT binds directly and specifically to the $c t x$ and $t c p A$ promoters and plays two roles in regulating their expression: antagonism of $\mathrm{H}-\mathrm{NS}$ and stimulation of RNAP. 


\section{Results}

Transcription activation of ctx by ToxT in V. cholerae

Previous experiments provided evidence that ToxT directly activates several promoters including those of $c t x$ and tcpA (DiRita et al., 1991). To begin characterizing the mechanism by which ToxT activates these genes, ctx reporter plasmids were constructed by fusing varying amounts of $c t x$ upstream to a promoterless lac $Z$ gene in the plasmid pTL61T (Linn and Pierre, 1990). The ctx promoter region contains three to eight direct tandem repeats of the heptamer sequence TTTTGAT, varying from strain to strain. The particular ctx promoter region studied in this work was amplified from the classical Inaba strain 569B which contains eight direct repeats of TTTTGAT. The $5^{\prime}-$ end-points for these $c t x-l a c Z$ fusions, relative to the ToxTdependent transcription +1 start site, are: $-400,-220$, $-111,-104,-97,-90,-83,-76,-69,-62,-55$ and -21 , and each has a $3^{\prime}$ end-point of +61 . To remove the putative -10 basal promoter element, an additional construct, $\Delta-10$, was made in which promoter DNA extending from -400 to -15 was fused to lacZ.

The $c t x-l a c Z$ fusions were tested for their ability to direct synthesis of $\beta$-galactosidase after mobilization into $V$. cholerae tox $R$ mutant strains carrying a toxT-encoding plasmid or vector alone (Krukonis et al., 2000)(see Discussion). Constructs with upstream end-points, from -400 through -76 , all directed high levels of ToxT-dependent $\beta$-galactosidase activity, whereas constructs $-69,-62$ and -55 expressed reduced levels of $\beta$-galactosidase activity in both backgrounds (Fig. 1A). As predicted, the -21 construct and the $\Delta-10$ construct, which lack the putative -35 and -10 basal promoter elements, respectively, expressed reduced levels of $\beta$-galactosidase in both backgrounds. From these results, we conclude that a minimum of three direct repeats (the number remaining in the -76 construct) of the sequence TTTTGAT is required for ToxTdependent activation of the ctx promoter.

\section{Role of ToxT and H-NS in transcription activation of ctx in $\mathrm{E}$. coli}

To further test the hypothesis that ToxT itself, as opposed to a ToxT-regulated factor, is the direct activator of the $c t x$ promoter, $\beta$-galactosidase activity of the $c t x-l a c Z$ fusions was assayed in an $E$. coli background so that any $V$. cholerae-specific factors that ToxT might require would not be present. For this experiment, the same $c t x-l a c Z$ fusion plasmids were mobilized into an $E$. coli strain (K5971) carrying the toxT-encoding plasmid (pMMTT) or the vector pMMB208 alone (Higgins et al., 1988; Morales et al., 1991; Higgins and DiRita, 1994). Similar results were observed as in the $V$. cholerae background, in which DNA from at least 76 nucleotides upstream of +1 , which
$\boldsymbol{A}$

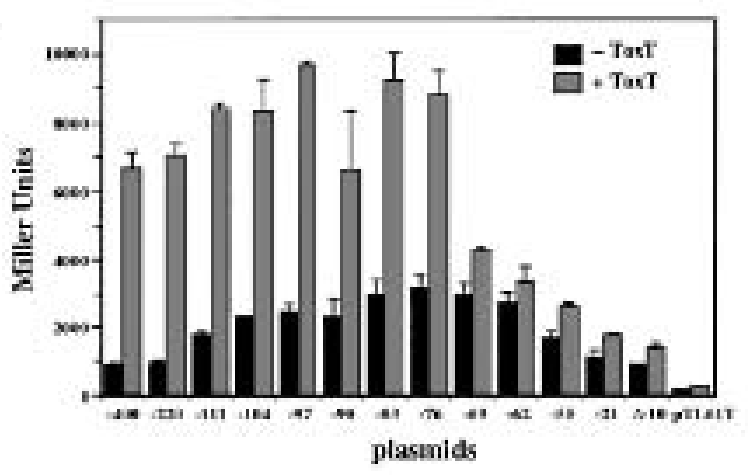

B

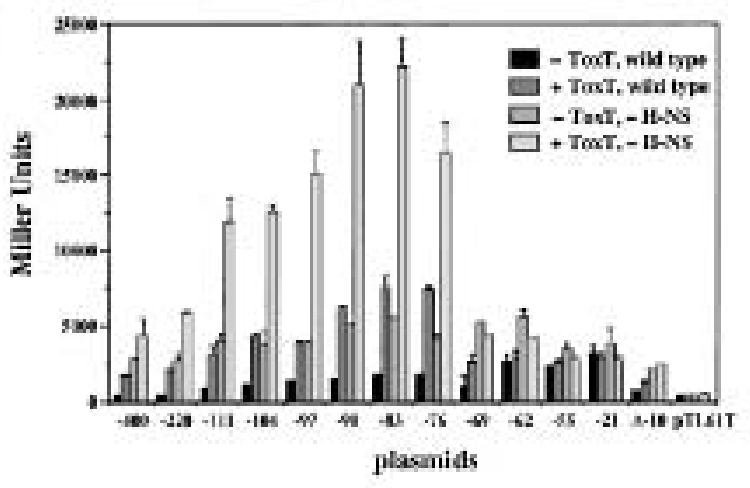

Fig. 1. Analysis of $c t x-l a c Z$ operon fusions in V. cholerae and $E$. coli. $V$. cholerae and $E$. coli strains containing the recombinant plasmids carrying various portions of the ctx promoter were grown at $37^{\circ} \mathrm{C}$ overnight, diluted $1: 100$ in fresh LB medium $+1 \mathrm{mM}$ IPTG and incubated at $30^{\circ} \mathrm{C}$ for $3 \mathrm{~h}$. $\beta$-Galactosidase activity was measured in Miller Units.

A. -ToxT and +ToxT represent a $V$. cholerae tox $R$ mutant strain (EK307) carrying plasmids pMMB208 and pMMTT (toxT gene cloned into pMMB208 under the control of a tac promoter) respectively.

B. Wild type and -H-NS represent E. coli strain K5971 and an osmZ (hns) mutant strain K5972 respectively. -ToxT and +ToxT represent E. coli strains carrying plasmids pMMB208 and pMMTT respectively.

includes three TTTTGAT repeats, was required for ToxTdependent activation (Fig. 1B). In addition, in both $V$. cholerae and $E$. coli, deletion of upstream DNA between -400 and -69 resulted in a progressive increase in basal transcription, suggesting that there may be a negative regulator in both $V$. cholerae and $E$. coli operating at the upstream promoter region of $c t x$. Nye and colleagues have shown that $\mathrm{H}-\mathrm{NS}$ exerts a negative effect at the $c t x$ promoter (Nye et al., 2000). H-NS mediates chromosomal DNA condensation in bacteria, and tends to bind to ATrich sequences. Therefore, we tested the role of $\mathrm{H}-\mathrm{NS}$ in activation of the ctx promoter by ToxT.

The $c t x-l a c Z$ fusion plasmids were mobilized into an $E$. coli hns ${ }^{-}$strain (K5972) carrying a toxT-encoding plasmid (pMMTT) or the vector pMMB208 alone (Higgins et al., 1988). The general activation pattern was similar to that in the wild-type background, in which three direct repeats 
of TTTTGAT were required for ToxT-dependent activation (Fig. 1B). However, the level of activation by ToxT was much higher in the hns $^{-}$background than in the wild type. The level of $\beta$-galactosidase activity in cells lacking H-NS surpassed ToxT-dependent activation in $\mathrm{H}_{-} \mathrm{NS}^{+}$cells. Nevertheless, derepression by the removal of $\mathrm{H}-\mathrm{NS}$ did not lead to full activation of the ctx promoter, as the presence of ToxT enhanced the level of activation further even in the absence of H-NS. These results confirm the observations of Nye and colleagues suggesting that $\mathrm{H}-\mathrm{NS}$ mediates repression of the ctx promoter that is counteracted by ToxT, and demonstrate that ToxT stimulates maximal transcription activation, presumably through interactions with RNAP.

Transcription activation of tcpA by ToxT in $\mathrm{V}$. cholerae and $\mathrm{E}$. coli

To analyse promoter requirements for activation of $t c p A$ by ToxT, several tcpA reporter plasmids were constructed by fusing varying amounts of $\operatorname{tcp} A$ promoter upstream to a promoterless lacZ gene in plasmid pTL61T. The $5^{\prime}$-endpoints for these $t c p A-l a c Z$ fusions, relative to the ToxTdependent transcription +1 start site, are $-475,-285$, $-185,-135,-85,-41$, and -21 , and each has a 3 ' endpoint of +55 . To remove the putative -10 basal promoter element, a $\Delta-10$ construct was made in which promoter DNA extending from -475 to -13 was fused to lacZ.

The tcpA-lacZ fusions were tested for their ability to direct synthesis of $\beta$-galactosidase in both wild type (O395) and toxT mutant (VJ740) V. cholerae (Champion et al., 1997). As seen in Fig. 2A, constructs with upstream end-points, from -475 through -85 , all directed high levels of ToxT-dependent $\beta$-galactosidase activity, whereas construct -41 expressed low levels of $\beta$-galactosidase activity in both backgrounds. As predicted, the -21 construct and the $\Delta-10$ construct, which lack the putative -35 and -10 basal promoter elements, respectively, expressed low levels of $\beta$-galactosidase in both strain backgrounds. From these results, we conclude that the region from -85 to -41 in the $t c p A$ promoter contains elements that are responsive to ToxT-dependent activation.

When these constructs were tested in $E$. coli, similar results were observed as in the $V$. cholerae background. $5^{\prime}$ deletions up to -85 directed high levels of ToxTdependent $\beta$-galactosidase activity whereas construct -41 did not (Fig. 2B). Unlike what we observed with the ctx promoter, basal expression of the tcpA promoter was less affected by deletion of the upstream sequences, implying that repression by a factor such as $\mathrm{H}-\mathrm{NS}$ is not a prominent feature in $t c p A$ regulation. To test the effect of $\mathrm{H}-\mathrm{NS}$, tcpA-lacZ fusion plasmids were mobilized into an E. coli $h_{n s^{-}}$strain background (K5972) carrying pMMTT or vector pMMB208. Again, similar results were
A

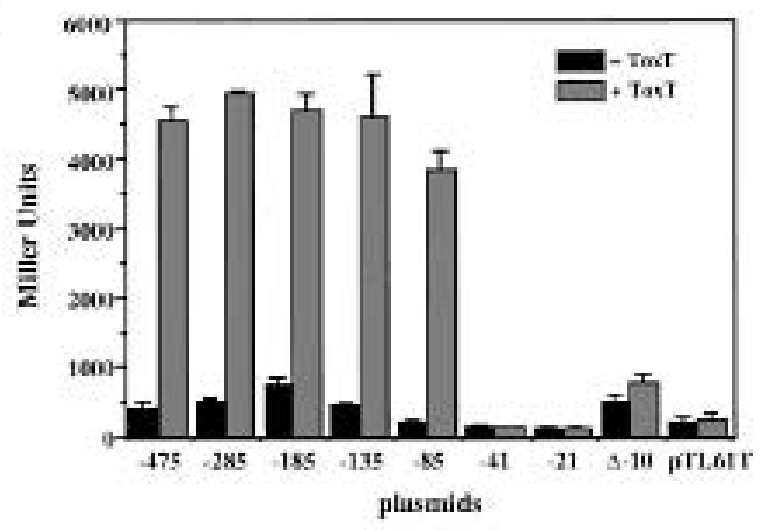

B

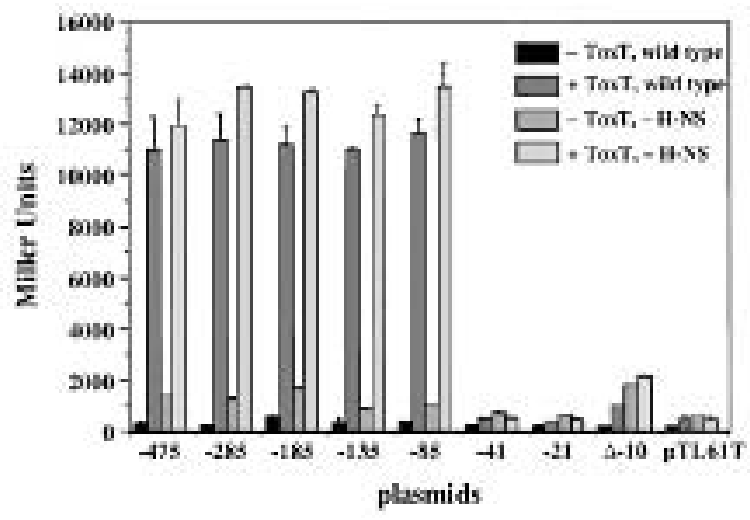

Fig. 2. Analysis of $t c p A-l a c Z$ operon fusions in $V$. cholerae and $E$. coli. V. cholerae and E. coli strains containing the recombinant plasmids carrying various portions of $t c p A$ promoter were grown at $37^{\circ} \mathrm{C}$ overnight, diluted $1: 100$ in fresh LB medium (A) or fresh LB medium $+1 \mathrm{mM}$ IPTG (B) and incubated at $30^{\circ} \mathrm{C}$ for $3 \mathrm{~h}$. $\beta$ Galactosidase activity was measured in Miller Units. A. -ToxT and +ToxT represent $V$. cholerae wild-type 0395 and a toxT mutant (tox $\left.T_{\text {EEtht }}\right)$ strain respectively.

B. Wild type and -H-NS represent E. coli strain K5971 and an osmZ (hns) mutant strain K5972 respectively. -ToxT and +ToxT represent $E$. coli strains carrying plasmids pMMB208 and pMMTT (toxT gene cloned into pMMB208 under the control of a tac promoter) respectively.

observed in which constructs -475 through -85 still exhibited ToxT-dependent activation. In the absence of H-NS, the level of $\beta$-galactosidase activation was generally threefold higher than in the presence of H-NS. Therefore, we conclude that $\mathrm{H}$-NS protein also negatively regulates the tcpA promoter. Based on the different behaviors of lacZ gene fusions with varying amounts of DNA from the tcp $A$ and ctxpromoters, we also conclude that the interaction of ToxT and $\mathrm{H}-\mathrm{NS}$ with each promoter is different. This will be discussed in greater detail below.

\section{Analysis of ToxT binding to the ctx and tcpA promoters}

To gain more specific insights into ToxT function, a $6 \times$ histidine-tagged form of ToxT protein (6H-ToxT) was over- 
expressed and purified. DNA binding by $6 \mathrm{H}$-ToxT was assessed by electrophoretic mobility shift assays (EMSA). For ctx promoter binding, a DNA fragment representing -181 to +7 relative to the +1 transcription start site, was used. For $t c p A$ binding, a DNA fragment representing

A

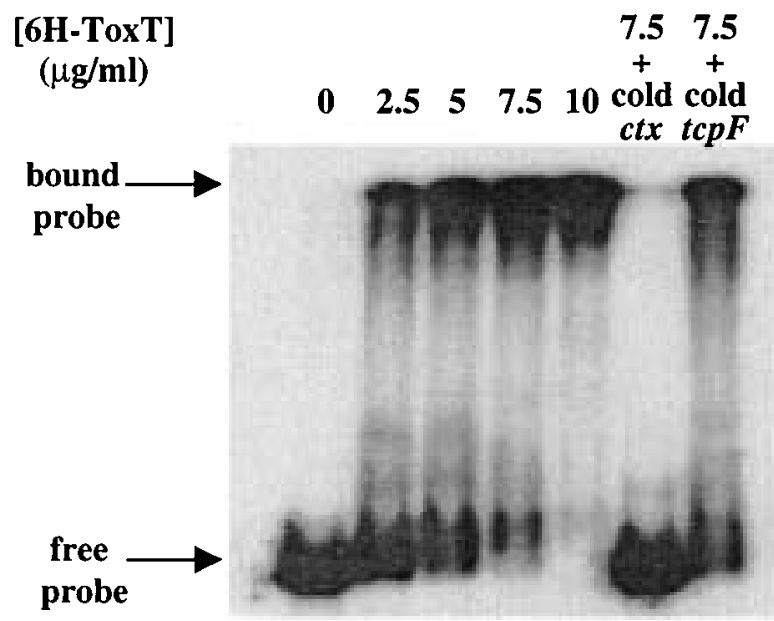

B
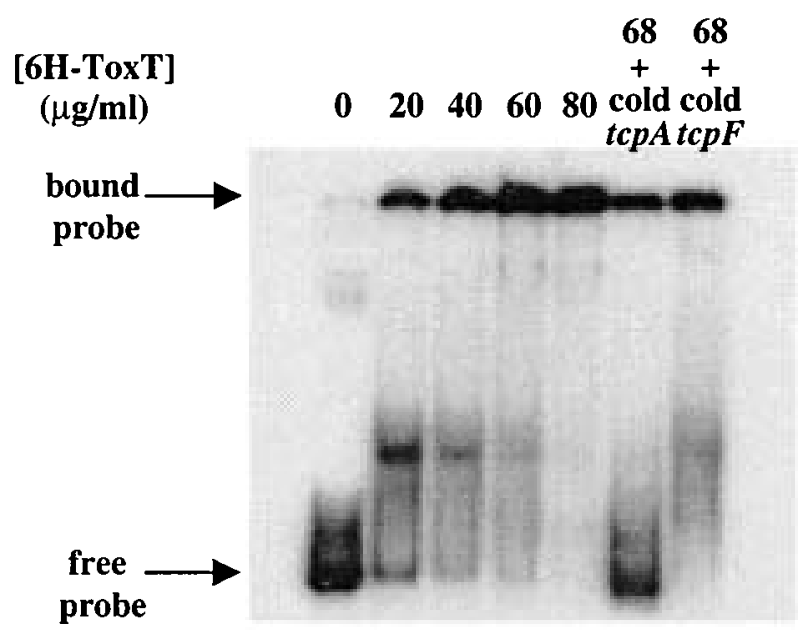

Fig. 3. Electrophoretic mobility shift assay for ToxT binding to the ctx and tcpA promoter DNA.

A. A restriction fragment containing the ctx promoter, from -181 to +7 relative to the +1 transcription start site.

B. A restriction fragment containing the tcpA promoter, from -185 to +55 , were radiolabelled on one strand. The labelled probes were incubated with various amounts of purified $6 \mathrm{H}-\mathrm{ToxT}$ protein at $30^{\circ} \mathrm{C}$ for $30 \mathrm{~min}$, then subjected to electrophoresis in a $6 \%$ nondenaturing polyacrylamide gel. 'Cold' represents excess nonradiolabelled promoter DNA that was used to compete with the radiolabelled $c t x$ or $t c p A$ probe. A DNA probe corresponding to tcpF ORF was used as a negative control to show specificity of ToxT binding.

(C) 2002 Blackwell Science Ltd, Molecular Microbiology, 43, 119-134
-185 to +55 relative to the +1 transcription start site, was used. Binding to radiolabelled DNA was performed as described in Experimental procedures. 6H-ToxT bound directly to each promoter fragment and binding was competed by addition of unlabelled probe DNA but not by unlabelled tcpF DNA, demonstrating the specificity of the binding (Fig. 3).

Determination of the ToxT binding sites in the ctx and tcpA promoters by DNase I protection

To determine the sequence within these promoters to which ToxT binds, DNase I footprinting experiments were performed. Radiolabelled DNA fragments that had been used in EMSA (described above) were incubated with increasing amounts of $6 \mathrm{H}$-ToxT, then digested by DNase I as described in Experimental procedures. The reactions were then subjected to electrophoresis on a denaturing polyacrylamide gel. In the ctx promoter, the region from -111 to -41 was protected by ToxT at the lowest concentration used. When higher concentrations of ToxT were used in the reactions, additional regions were protected by ToxT; taking both strands into account, the limits of the additional protected regions are from -118 to -112 and from -40 to -13 (Fig. 4). These data suggest that there may be two ToxT binding sites with different affinity: upstream sites with higher affinity and a downstream site closer to the basal promoter elements with lower affinity. Included within the binding sites for $6 \mathrm{H}$-ToxT are the direct repeats made up of the element TTTTGAT, which are also within the binding sites for ToxR in the $c t x$ promoter (Pfau and Taylor, 1996; Li et al., 2000). This sequence overlaps with the consensus binding site for $\mathrm{H}$ NS, TNTNAN, at which $\mathrm{N}$ is any nucleotide (Rimsky and Spassky, 1990).

The protected region within the tcpA promoter, taking both strands into account, extended from -84 to -41 (Fig. 5). The DNase I footprinting results are consistent with results from the genetic analysis of the tcpA promoter shown above (Fig. 2). A summary of the ToxT binding sites in the $c t x$ and $t c p A$ promoters is shown in Fig. 6. Two features are worth noting here: (i) there is no apparent primary sequence similarity between the binding sites in these two promoters; and (ii) ToxT binds to the ctx promoter at sites of at least two different affinities, whereas it binds to the tcpA promoter at a site of a single apparent affinity.

\section{Hybrid ctx-tcpA promoter acts like a class I promoter}

DNase I footprinting results suggested that there may be two ToxT binding sites in the ctx promoter. To test whether occupation of the downstream lower affinity site is a consequence of ToxT binding to the upstream higher affinity 
A

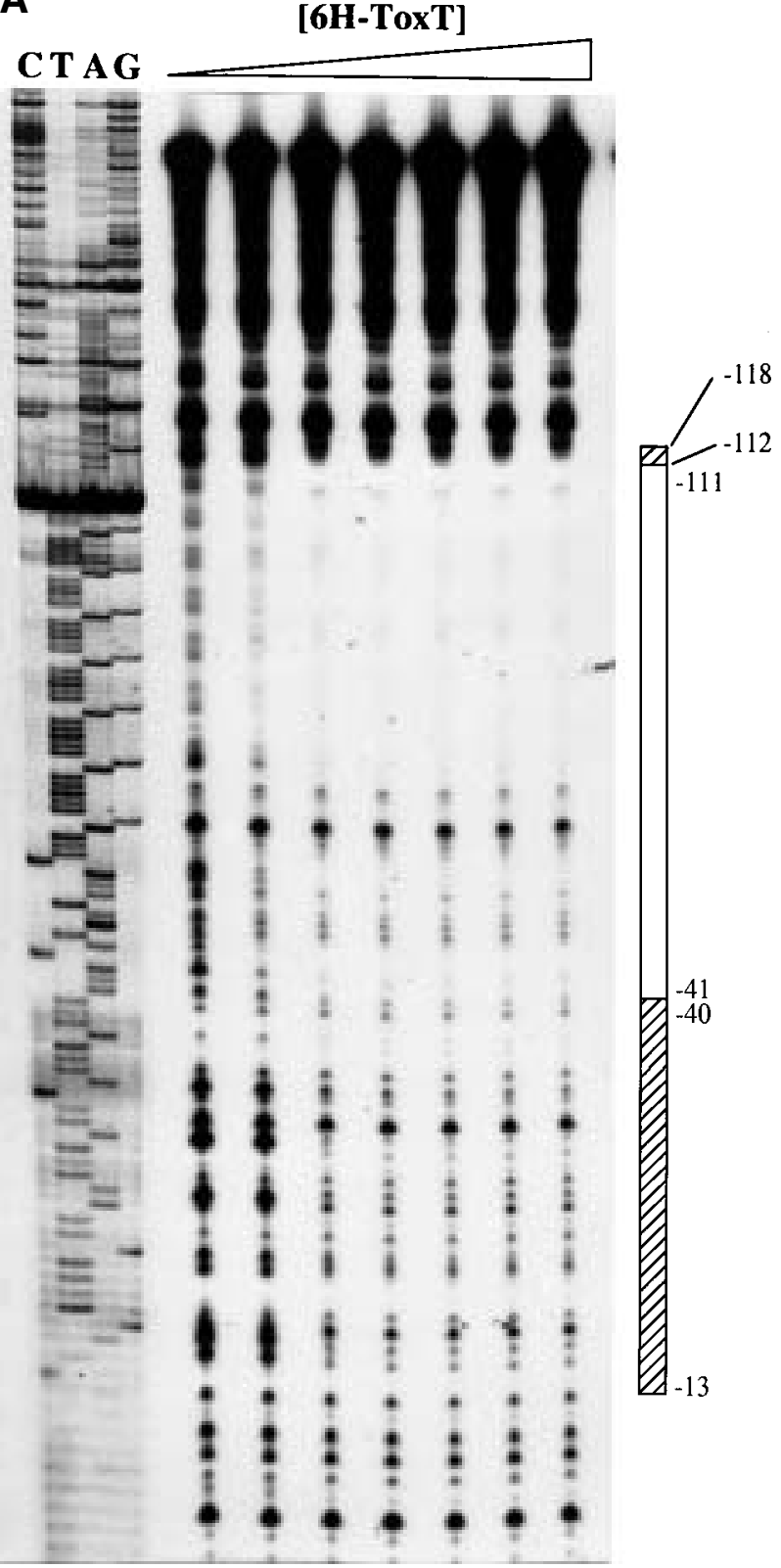

B

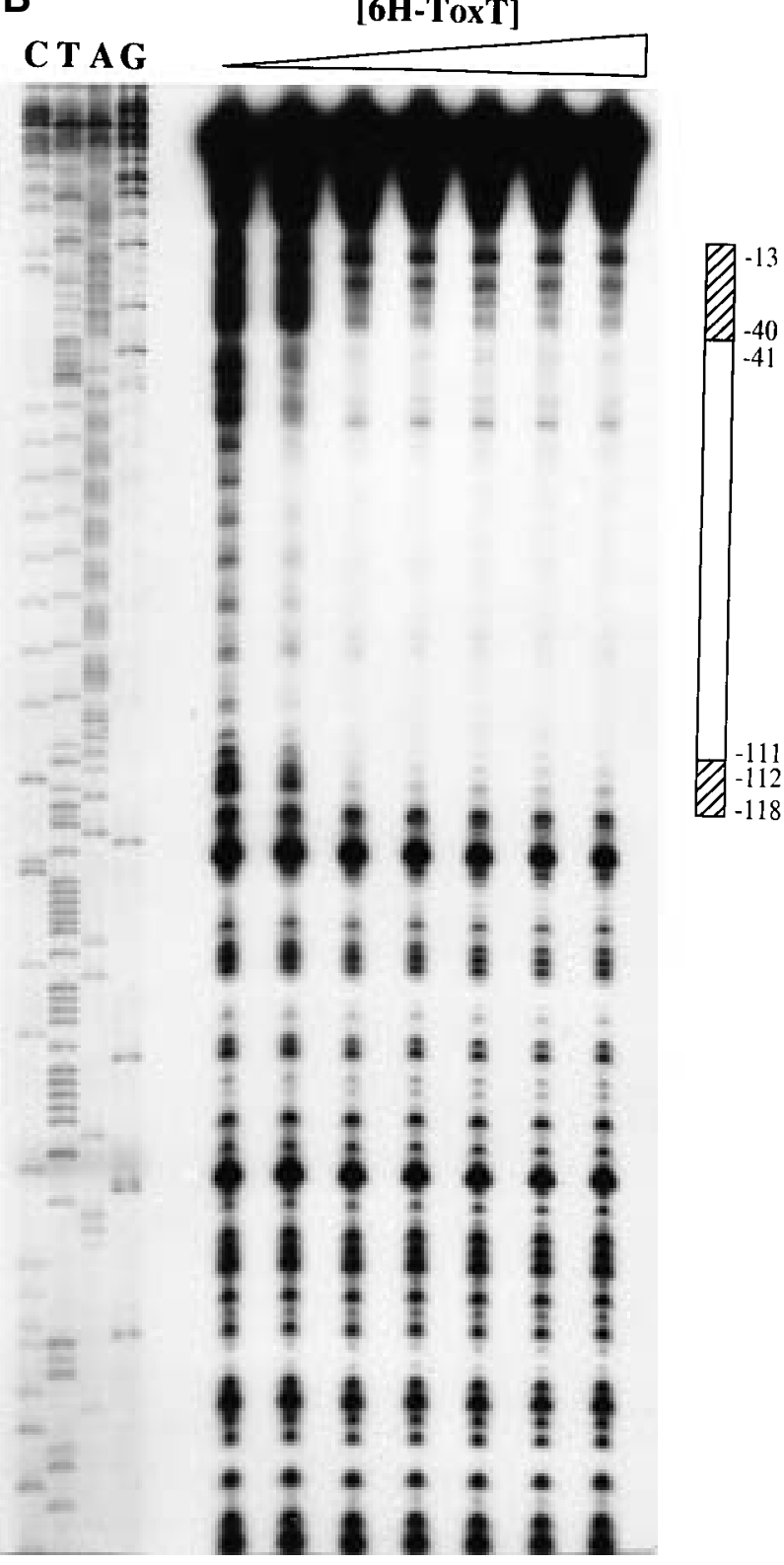

Fig. 4. DNase I footprinting of ToxT in the ctx promoter. Restriction fragments containing -151 to +7 of the $c t x$ promoter region were radiolabelled on one strand ( $\mathrm{A}$ is the top strand, $\mathrm{B}$ is the bottom strand) and subjected to DNase I footprinting. The $c t x$ probes were incubated with various amounts of $6 \mathrm{H}-\mathrm{ToxT}$ at $30^{\circ} \mathrm{C}$ for $30 \mathrm{~min}$. Then, $0.04 \mathrm{U}$ of DNase I was added to the mixture and incubated at room temperature for $2 \mathrm{~min}$. The reaction was stopped and extracted with phenol-chloroform. The DNA sequence ladders of the corresponding promoter region are shown on the left. The triangles above the figures represent increasing amount of $6 \mathrm{H}$-ToxT used $(0,11,56,100,145,190$ and $234 \mathrm{nM})$. The open bars to the side of the figures represent regions protected by low concentrations of ToxT, the hatched bars represent regions protected by high concentrations of ToxT, and are labelled relative to the +1 transcription start site.

sites that include the TTTTGAT repeats, a hybrid promoter was constructed by fusing -76 to -41 of the $c t x$ promoter to -40 to +55 of the tcpA promoter. This chimeric promoter contains the minimal region for ToxT-dependent ctx activation which is also part of the high affinity ToxT binding sites in the $c t x$ promoter (Figs 1 and 4), and the downstream portion of the tcpA promoter which is neither activated when fused by itself to lacZ nor protected by ToxT (Figs 2 and 5).

The hybrid promoter was fused to a promoterless lac $Z$ gene in PTL61T, and the fusion plasmid was tested for its ability to direct $\beta$-galactosidase synthesis in an $E$. coli strain (K5971) carrying the toxT-encoding plasmid (pMMTT) or the vector pMMB208 alone. This chimeric 
A

\section{T AG}

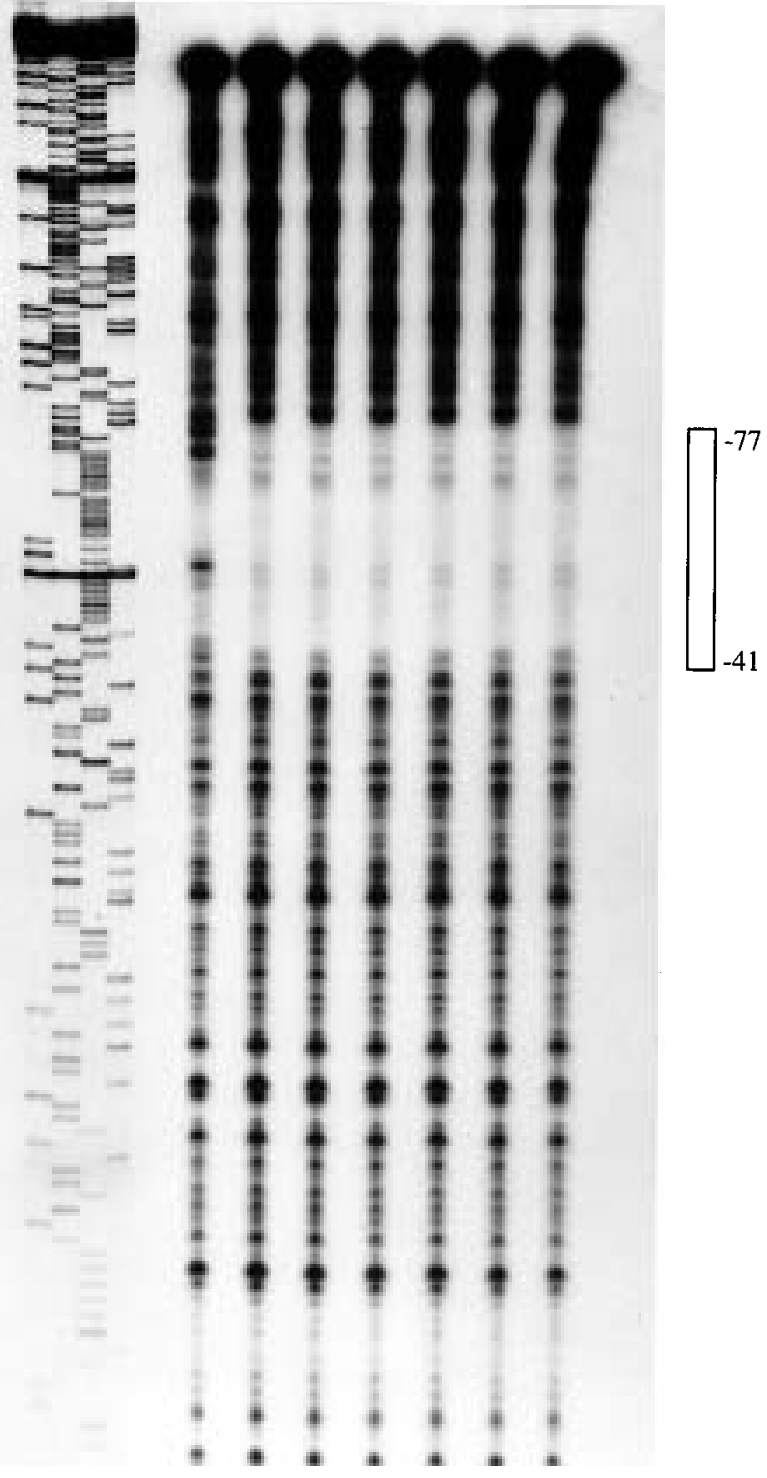

B

\section{[6H-ToxT]}

\section{T AG}

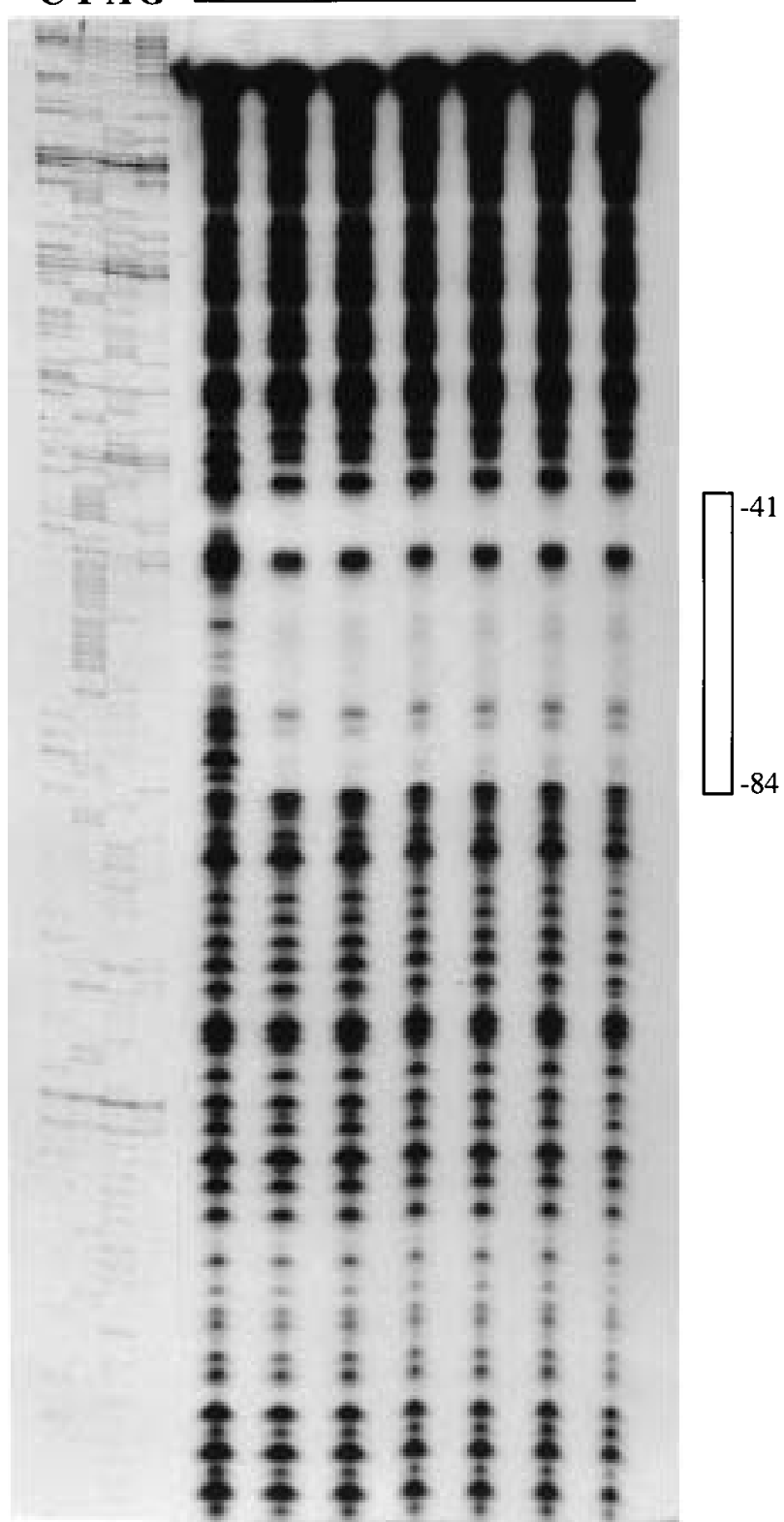

Fig. 5. DNase I footprinting of ToxT in the tcpA promoter. Restriction fragments corresponding to -185 to +55 of the tcpA promoter region were radiolabelled on one strand ( $\mathrm{A}$ is the top strand, $\mathrm{B}$ is the bottom strand) and subjected to DNase I footprinting. The tcpA probes were treated similarly as the ctx probes in Fig. 4. The DNA sequence ladders of the corresponding promoter region are shown on the left. The triangles above the figures represent increasing amount of $6 \mathrm{H}$-ToxT used $(0,178,889,1601,2313,3024$ and $3735 \mathrm{nM})$. The open bars to the side of the figures represent regions protected by ToxT, and are labelled relative to the +1 transcription start site.

promoter construct expressed high levels of $\beta$-galactosidase activity in the presence of ToxT, even higher than that of the original $c t x$ promoter deletion construct -76 (Fig. 7A). We next tested whether the downstream sequence of the chimeric promoter is bound by ToxT, leading to transcription activation. If the direct repeats of the ctx promoter can direct ToxT binding to the down- stream promoter region which overlaps the -35 hexamer, then the $t c p A$ portion of the hybrid promoter is predicted to be bound by ToxT. DNase I footprinting analysis of the radiolabelled chimeric promoter fragment showed that only the region corresponding to -76 to -41 of the $c t x$ promoter was protected by ToxT, but not the downstream tcpA promoter region (Fig. 7B). These results suggest that 
ctx promoter:

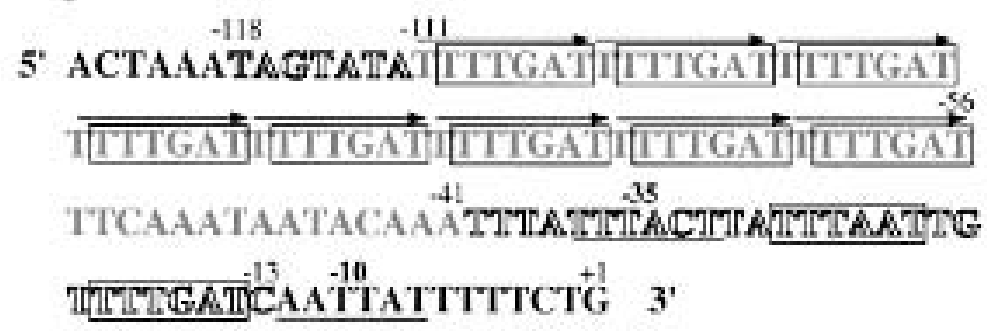

tcpA promoter:

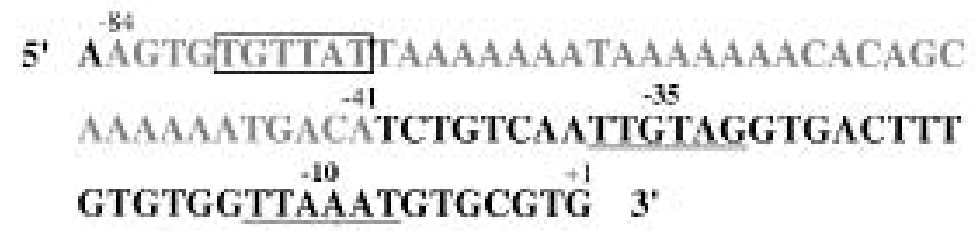

Fig. 6. Sequence of ToxT binding sites in the ctx and tcpA promoters.

A. ToxT has two sites of different affinity in the $c t x$ promoter. The higher affinity sites are highlighted in grey and consisted of eight direct repeats (indicated by arrows above the sequence) plus the downstream flanking sequences. The lower affinity sites are from -118 to -112 , and from -40 to -13 , and are indicated by the outlined letters. Each arrow represent one heptamer repeat, TTTTGAT. $\mathrm{B}$. ToxT binding sites in the tcpA promoter from -84 to -41 are highlighted in grey. The $5^{\prime}$ and $3^{\prime}$ orientations of the promoter regions are shown, and +1 is the transcription start site of $c t x$ or $t c p A$. The -35 and -10 putative RNAP binding elements are underlined. Sequences highlighted by the black boxes are general consensus $\mathrm{H}-\mathrm{NS}$ binding sites, TNTNAN, in which $\mathrm{N}$ is any nucleotide.
ToxT binding to the higher affinity sites in the $c t x$ promoter does not necessarily direct more ToxT into binding downstream sequences closer to the basal promoter elements. Therefore, this chimeric promoter behaves more like the tcpA promoter, as a class I promoter, as opposed to the ctx promoter which is similar to a class II promoter.

In vitro transcription activation of the ctx and tcpA promoters by ToxT

Based on our data from experiments using the E. coli $\mathrm{hns}^{-}$ mutant, it appears that ToxT does not simply displace $\mathrm{H}$ NS and relieve its repression on the promoters, as ToxT further enhanced transcription activation even in the absence of H-NS (Figs $1 \mathrm{~B}$ and $2 \mathrm{~B}$ ). To test directly whether ToxT activates transcription, rather than simply displacing the repressor, we tested activation by $6 \mathrm{H}$-ToxT in an in vitro transcription system, using plasmids harbouring the $c t x$ or the tcpA promoter as the DNA template. When both ToxT and RNAP were present in the reaction, 375- and 369-nucleotide transcripts were generated from the $c t x$ promoter- and tcpA promoter-encoding plasmids, respectively, as predicted by the location of the transcription terminator in the templates (Fig. 8, lanes 4 and 5). In the absence of either ToxT or RNAP, transcription was severely diminished (lanes 2 and 6). RNAP activated transcription of both promoters at very low levels (lane 2 and data not shown), and addition of ToxT greatly enhanced the level of transcripts generated, indicating that ToxT directly stimulates RNAP to activate transcription at these promoters. Therefore, we conclude that ToxT plays two roles in activating transcription: (i) it inhibits the effect of $\mathrm{H}-\mathrm{NS}$, perhaps by displacement if $\mathrm{H}-\mathrm{NS}$ is bound to sites in the ctx promoter; and (ii) it directly stimulates RNAP. When both the $c t x$ and tcpA promoter-encoding plasmids were used in the same reaction in a 1:1 ratio, a greater amount of ctx promoter-driven transcript was detected than tcpA promoter-driven transcript (lane 1). This is consistent with the in vivo data from lacZ fusions suggesting that $c t x$ is a more efficient ToxT-dependent promoter than tcpA.

\section{Discussion}

This report describes a study aimed at characterizing requirements for ToxT-dependent transcription of $c t x$ and $\operatorname{tcp} A$, which encode two major virulence factors, the cholera toxin (CTX) and the toxin co-regulated pilus (TCP). The data presented here lead us to conclude that ToxT is the direct activator of $c t x$ and tcpA. Although both promoters are activated directly by ToxT, $c t x$ transcription regulation is more complex than $t c p A$. A stronger repressing effect by $\mathrm{H}-\mathrm{NS}$ on $c t x$ than on $\operatorname{tcp} A$ was observed (Figs $1 \mathrm{~B}$ and $2 \mathrm{~B}$ ). For the ctx promoter, the removal of $\mathrm{H}-\mathrm{NS}$ in E. coli derepressed the expression of $c t x-l a c Z$ fusions and led to high level of expression even in the absence of ToxT. This suggests that ToxT possibly counteracts H-NS repression at the ctx promoter under inducing conditions. In contrast, although the basal level of activation of tcpA-lacZ transcriptional fusions was increased in the absence of $\mathrm{H}-\mathrm{NS}$, ToxT was still required to achieve maximal levels of activation. In vitro transcription reactions also demonstrated that when both promoters were present in the same reaction, ctx was transcribed at a higher level than $\operatorname{tcp} A$ (Fig. 8). These in vitro data reflect what we observed in vivo, in which 
A
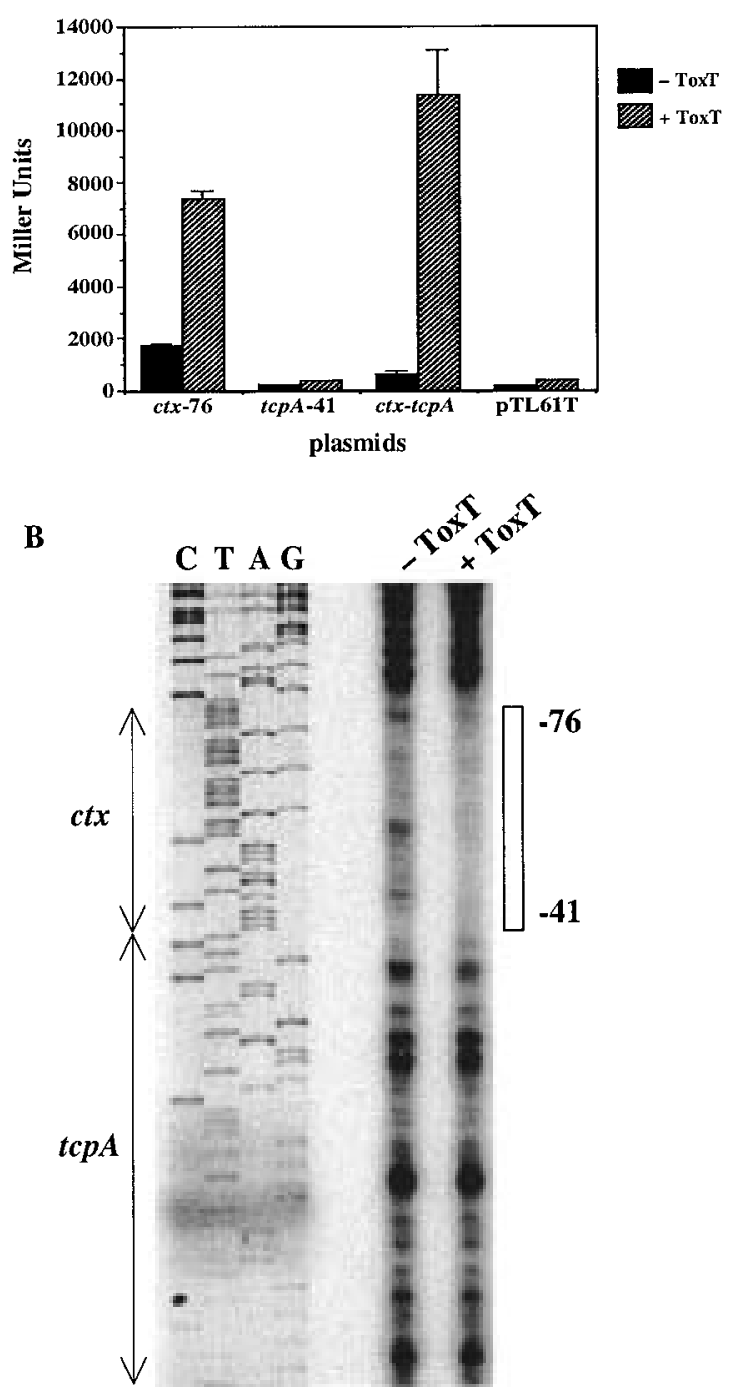

Fig. 7. Analysis of $c t x-t c p A$ hybrid promoter.

A. Analysis of $c t x-t c p A-l a c Z$ operon fusion in E. coli. E. coli strains containing the recombinant plasmids carrying various portions of $c t x, \operatorname{tcp} A$ and $c t x-t c p A$ hybrid promoter and empty vector pTL61T were grown at $37^{\circ} \mathrm{C}$ overnight, diluted $1: 100$ in fresh LB medium $+1 \mathrm{mM}$ IPTG and incubated at $30^{\circ} \mathrm{C}$ for $3 \mathrm{~h}$. $\beta$-Galactosidase activity was measured in Miller Units. -ToxT and + ToxT represent an $E$. coli strain (K5971) carrying plasmids pMMB208 and pMMTT (toxT gene cloned into pMMB208 under the control of a tac promoter) respectively.

B. DNase I footprinting of ToxT in the hybrid promoter. Restriction fragment corresponding to -74 to -41 of $c t x$ fused to -40 to +55 of tcpA was radiolabelled on one strand and subjected to DNase I footprinting. The probe was incubated with or without $6 \mathrm{H}$-ToxT at $30^{\circ} \mathrm{C}$ for $30 \mathrm{~min}$. Then, $0.04 \mathrm{U}$ of DNase I was added to the mixture and incubated at room temperature for $2 \mathrm{~min}$. The reaction was then stopped and extracted with phenol-chloroform. The DNA sequence ladder of the same region is shown on the left. The ctx and $\operatorname{tcp} A$ promoter portions of the chimera are indicated with arrows on the left. -ToxT and +ToxT represent 0 and $446 \mathrm{nM}$ of $6 \mathrm{H}-$ ToxT used, respectively. The open bar to the side of the figure represents regions protected by ToxT, and is labelled relative to the +1 transcription start site. $c t x-l a c Z$ is more highly activated than tcpA-lacZ (Figs 1 and 2). This is probably because ToxT is more efficient in binding to the ctx promoter than the $\operatorname{tcp} A$ promoter, at least in the absence of $\mathrm{H}-\mathrm{NS}$, as demonstrated by the lower concentrations of $6 \mathrm{H}-\mathrm{ToxT}$ required to shift and protect $c t x$ than $t c p A$ in the EMSA and DNase I footprinting experiments. Therefore, in the absence of $\mathrm{H}-\mathrm{NS}$ in the in vitro transcription system, the ctx promoter was transcribed more efficiently when ToxT was added. In addition, when both the ctx and tcpA promoters were present in the same in vitro transcription reaction, in the absence of ToxT, ctx was also expressed to some degree but expression of $t c p A$ was almost undetectable (Fig. 8). This observation could be attributed to the smaller effect of $\mathrm{H}$ NS on the tcpA promoter, such that the mere absence of $\mathrm{H}-\mathrm{NS}$ does not lead to significant transcription activation, and ToxT protein is required to achieve full activation of the tcpA promoter. This is similar to the genetic data from the lacZ fusion analysis (Figs $1 \mathrm{~B}$ and $2 \mathrm{~B}$ ).

The reason why $\mathrm{H}-\mathrm{NS}$ has a stronger effect on $c t x$ than $\operatorname{tcp} A$ can probably be attributed to the fact that $c t x$ has more potential binding sites for H-NS. The general consensus binding sites for H-NS is TNTNAN, in which $\mathrm{N}$ is any nucleotide. Therefore, each direct repeat TTTTGAT includes a binding site for H-NS (TTTGAT) (Fig. 6). These data agree with the recent findings of Nye and colleagues in which $\mathrm{H}-\mathrm{NS}$ exerts a stronger negative effect on the $c t x$ than on the tcpA promoter in $V$. cholerae (Nye et al., 2000). The stronger apparent effect of $\mathrm{H}-\mathrm{NS}$ on $c t x$ than on $\operatorname{tcp} A$ may contribute to gene regulation in vivo. Lee
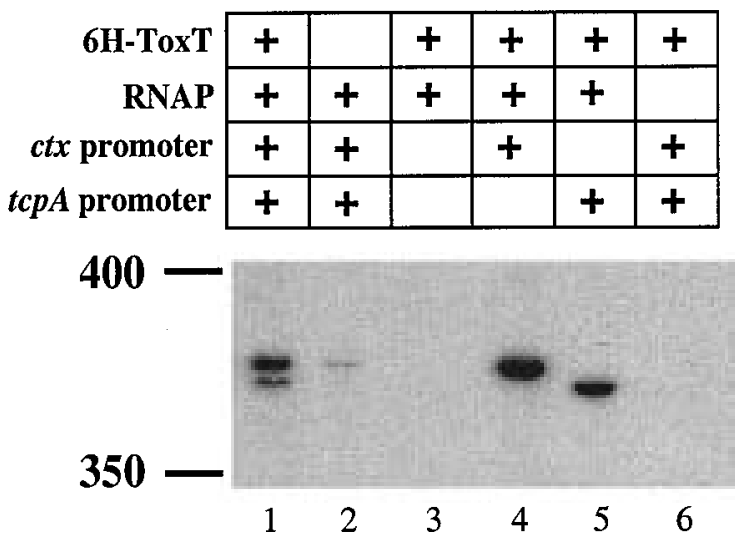

Fig. 8. In vitro transcription analyses of the $c t x$ and $\operatorname{tcp} A$ promoters. A single round of transcription was initiated in reaction mixtures containing DNA template plasmid encoding either the $c t x$ or tcpA promoter, purified E. coli RNAP, and/or $6 \mathrm{H}$-ToxT, in which the presence of each component in the reactions is indicated by a ' + ' above the lanes. Samples were run on a $6 \%$ sequencing gel. The size of $c t x$ promoter- and $t c p A$ promoter-driven transcripts is 375- and 369-nucleotides respectively. In the absence of both the ctx and tcpA promoter encoding plasmids (lane 3), the empty vector pTE103 was used as a control. 
and colleagues showed that during infection, $\operatorname{tcp} A$ is expressed to its maximal level before $c t x$ is expressed to its maximal level (Lee et al., 1999). H-NS repression may contribute to the delayed activation of the ctx promoter which may not be activated until ToxT reaches a sufficient level through the autoregulatory loop that controls its expression (Yu and DiRita, 1999) to compete most effectively with $\mathrm{H}-\mathrm{NS}$ for binding.

The region bound by ToxT in the ctx promoter is larger than that in the $t c p A$ promoter. For $\operatorname{tcp} A$, ToxT binding sites extend from -84 to -41 . However, in the ctx promoter, ToxT has two sites of apparently different affinity. At low ToxT concentrations, sites from -111 to -41 are occupied. At high ToxT concentrations, the lower affinity sites from -118 to -112 , and from -40 to -13 , are subsequently occupied. The existence of sites with two different affinities has been observed in other promoters activated by AraC family activators. For example, VirF from Yersinia spp. has been shown to have strong and weak binding sites in several promoters, and there is a clear correlation between the VirF concentration and the VirF-binding site occupancy (Wattiau and Cornelis, 1994). The ToxT footprints in the ctx promoter extend beyond the region required for activation as defined by genetic means (deletion up to -76 could still be activated by ToxT), and this may reflect oligomerization of ToxT after recognition of a primary binding site in the ctx promoter as postulated for other members of the AraC family (Gallegoset al., 1997).

The ToxT footprints overlap the -35 promoter element in the ctx promoter, but not in tcpA. Many members of the AraC family have recognition sites located adjacent to or overlapping the -35 region of the corresponding promoters. Some examples of these are SoxS from E. coli (Fawcett and Wolf, 1995), VirF from Yersinia spp. (Wattiau and Cornelis, 1994), Rns from E. coli (Munson and Scott, 1999) and XyIS from Pseudomonas putida (Kaldalu et al., 1996). Like ToxT on the ctx promoter, many of these activators also have recognition sites located upstream of the -35 hexamer. For example, three independently regulated but homologous proteins, MarA, SoxS and Rob, activate a common set of promoters to regulate multiple antibiotic resistance, superoxide resistance and organic solvent tolerance respectively. These promoters are not stimulated to the same extent by all three activators, but they are sufficiently similar to be thought of as a single regulon. Each regulon promoter has a MarA/SoxS/Rob binding site, referred to as the 'marbox'. Promoters in which the marbox is located upstream of the -35 hexamer are termed 'class I promoters', and their activation requires interactions of MarA, SoxS or Rob with $\alpha-C T D$ of RNAP. This is similar to interactions between CAP and RNAP $\alpha$-CTD at the class I CAP-dependent promoters. Promoters in which the marbox overlaps the -35 hexamer are termed 'class II promoters', and their expression does not involve interaction of the activators with either RNAP $\alpha$-CTD or $\alpha$-NTD (Martin et al., 1999; Egan et al. 2000). These promoters are different from the class II CAPdependent promoters mentioned above, in which interactions between CAP and RNAP $\alpha$-CTD and $\alpha$-NTD are required for transcription activation. Recent studies with AraC and two AraC homologues, RhaS and Ada, revealed that when the binding sites of these activators overlap the -35 hexamer of their cognate promoters, they interact with the $\sigma$ subunit of RNAP (Landini and Busby, 1999; Bhende and Egan, 2000; Dhiman and Schleif, 2000). Based on observations with other AraC members and the nature of the two promoters, the $\operatorname{tcp} A$ promoter is similar to the class I promoters, and ToxT is predicted to interact with RNAP through $\alpha$-CTD at this promoter for transcription activation. The $c t x$ promoter is similar to the class II promoters, and ToxT is predicted to interact with the $\sigma$ subunit of RNAP at this promoter to activate transcription.

We also showed that a chimeric promoter, with -76 to -41 of $c t x$ fused to -40 to +55 of $t c p A$, was still activated by ToxT to high levels. In addition, DNase I footprinting analysis revealed that ToxT only protects the ctx promoter portion of this hybrid promoter, without overlapping the -35 region of the tcpA promoter (even when greater than 20 fold more $6 \mathrm{H}$-ToxT was used; data not shown), hence the chimeric promoter behaves more like a class I promoter than a class II promoter. We conclude that the higher affinity upstream ctx promoter region does not necessarily dictate ToxT binding to the downstream region. This may be because the downstream tcpA promoter region, like class I promoters, contributes more significantly to this chimeric promoter, and provides a mechanism for ToxT to interact with RNAP without overlapping the -35 element. Alternatively, the lower affinity ToxT binding site that overlaps the -35 region in the ctx promoter is not important for transcription activation. To test this hypothesis, construction of point mutations in the downstream lower affinity Tox $T$ binding region in the native ctx promoter is required.

There is no primary sequence similarity between the ctx and $\operatorname{tcp} A$ promoters beyond the fact that they are both AT-rich. One possible mechanism of ToxT function is that it binds to AT-rich sequences and further enhances bending of the promoter already caused by the runs of AT. This may enhance binding of RNAP and/or the rate of isomerization of the RNAP-promoter complex from closed to open state. In the case of the ctx promoter, binding of $\mathrm{H}$ NS may alter DNA conformation to an unfavourable topology for the formation of active transcription complexes, as in the case of $\mathrm{H}-\mathrm{NS}$ binding to the E. coli rrnB $\mathrm{P} 1$ promoter (Afflerbach et al., 1999). We predict that ToxT displaces $\mathrm{H}-\mathrm{NS}$ from the promoter and binds first to the high affinity sites (-111 to -41$)$, which may initiate an oligomeri- 

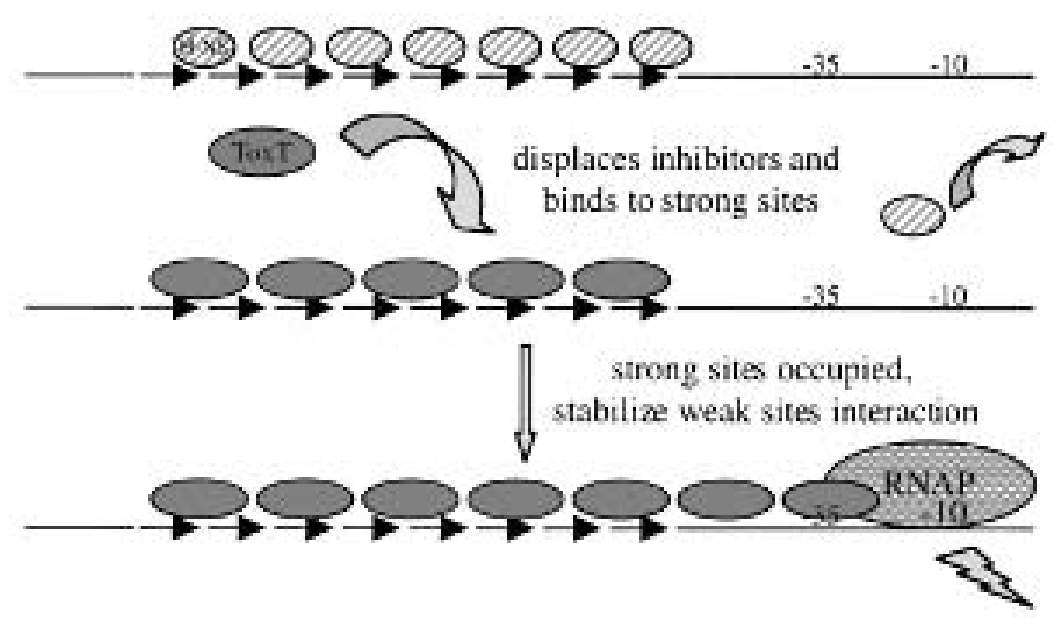

Fig. 9. Model for ToxT transcription activation. See text for details. Promoter region, in particular the $c t x$ promoter, is normally bound by H-NS. Under conditions favourable for ToxT-dependent gene expression, ToxT displaces $\mathrm{H}$-NS and first binds to the high affinity sites, then to the weak affinity sites, whose interaction is stabilized by the occupation of the high affinity sites. Transcription activation happens upon stimulation of RNAP by ToxT. Symbols: hatched ovals, H-NS; grey solid ovals, ToxT; large dotted oval, RNAP; arrows, one heptamer repeat (TTTTGAT) in the $c t x$ promoter; -35 and -10 , putative RNAP binding elements. zation process, and the low affinity sites that overlap the -35 hexamer are subsequently occupied. ToxT may then enhance the binding of RNAP to the promoter and/or help the isomerization of the RNAP-promoter closed to open complexes. This model is summarized in Fig. 9.

When the $c t x-l a c Z$ transcriptional fusions were mobilized into a $V$. cholerae toxT mutant background, nonToxT dependent activation was observed, almost as much as in the wild-type background (data not shown). This is probably as a result of ToxR activation of the ctx-lacZ fusions in the toxT mutant strain. This seems to conflict with the observation that in a $V$. cholerae tox $T$ mutant background, almost no CTX production was detected (Champion et al., 1997). However, DNA topology of the $c t x$ promoter in the transcription fusion plasmids is different from that of the chromosomal ctx promoter, so this may explain the discrepancy and why Tox $R$ alone in the absence of ToxT was apparently able to activate the $c t x-l a c Z$ transcription fusions. Lee and colleagues demonstrated ToxR dependence of $c t x$ expression in vivo (Lee et al., 1999), again suggesting that activation of the ctx promoter, during infection, may be regulated by topological constraints, perhaps through H-NS as described above. Nye and colleagues also demonstrated that the level of $c t x$ expression in an hns mutant lacking both ToxT and ToxR is lower than the level of expression in an $h n s$ mutant lacking only ToxT, and they suggested that this is because ToxR directly influences the ctx promoter in the absence of $h n s$ (Nye et al., 2000). However, it seems that overexpression of ToxR may overcome the topological constraint of the chromosomal ctx promoter, as ToxR expressed from a plasmid in E. coli activates $c t x-l a c Z$, but ToxR expressed from the chromosome in $V$. cholerae in the absence of ToxT does not (Miller and Mekalanos, 1984; Champion et al., 1997). The ToxR binding sites in the ctx promoter overlap the ToxT binding sites (Pfau and Taylor, 1996; Li et al., 2000; this work). ToxR may have a much lower affinity than ToxT for the sites in the ctx pro- moter, so overexpression might be required for binding and activation of $c t x$ by ToxR. In contrast to $c t x, \operatorname{tcp} A$ expression is dependent on ToxT with no evident effect of ToxR.

In summary, this report presents data showing that ToxT directly binds and activates the $c t x$ and $t c p A$ promoters. ToxT does not bind to obvious consensus primary sequences, but more likely to AT-rich regions that are intrinsically curved. ToxT binding to the promoters may further enhance DNA bending, prevent and/or displace $\mathrm{H}-\mathrm{NS}$ binding to the promoters under non-favourable conditions, and favour its interactions with RNAP leading to initiation of transcription activation.

\section{Experimental procedures}

\section{Bacterial strains and plasmids}

The $V$. cholerae and $E$. coli strains used in this study are listed in Table 1. Strains were grown in Luria Broth (LB) medium at $30^{\circ} \mathrm{C}$. The strains were maintained at $-70^{\circ} \mathrm{C}$ in $\mathrm{LB}$ medium plus $20 \%$ glycerol. Antibiotics were used at the following concentrations: ampicillin, $100 \mathrm{~g} \mathrm{~m} \mathrm{ml}^{-1}$; tetracycline, $12.5 \mathrm{~g} \mathrm{~m} \mathrm{ml}^{-1}$; kanamycin, $30 \mathrm{~g} \mathrm{~m} \mathrm{ml}^{-1}$; chloramphenicol, $25 \mathrm{\mu g} \mathrm{ml}^{-1}$; and streptomycin, $100 \mu \mathrm{g} \mathrm{ml}^{-1}$. Plasmids were introduced into $E$. coli strains by transformation and into $V$. cholerae strains through triparental mating with $E$. coli strain MM294 (pRK2013) as a donor of mobilization functions.

\section{DNA manipulations}

Plasmid DNA was purified with Qiagen columns (Qiagen). Polymerase chain reaction (PCR) was performed using the Expand High Fidelity PCR System (Roche) as specified by the manufacturer. PCR templates were 569B chromosomal DNA for the ctx promoter, or pCS2.1 for the tcpA promoter. Synthesized primers containing added recognition sequences for restriction endonucleases were used to facilitate directional cloning. PCR products were purified by agarose gel electrophoresis or native polyacrylamide gel 
Table 1. Strains and plasmids used in this study.

\begin{tabular}{|c|c|c|}
\hline Name & Description & Reference/source \\
\hline \multicolumn{3}{|l|}{ Strain } \\
\hline \multicolumn{3}{|l|}{ V. cholerae } \\
\hline $569 \mathrm{~B}$ & Wild-type, Classical Inaba, Str ${ }^{R}$ & Laboratory collection \\
\hline O395 & Wild-type, Classical Ogawa, Str ${ }^{R}$ & Laboratory collection \\
\hline VJ740 & O395 toxT $T_{\Delta h t h}$ & Champion et al. (1997) \\
\hline EK307 & O395 $\Delta$ toxR & Krukonis et al. (2000) \\
\hline \multicolumn{3}{|l|}{ E. coli } \\
\hline AAEC189 & $\begin{array}{l}\mathrm{F}^{-} \Delta \text { fim recA supE44 hsdR17 mcrA mcrB endA1hi-1 } \\
\Delta\left(\text { argF-lac)205(U169) } \lambda^{-}\right.\end{array}$ & Blomfield et al. (1991) \\
\hline $\mathrm{DH} 5 \alpha$ & $\begin{array}{l}\mathrm{F}^{-} \text {endA1 hsdR17 }\left(\mathrm{r}_{\mathrm{K}}^{-} \mathrm{m}_{\mathrm{K}}^{+}\right) \text {supE44 thi-1 recA1 gyrA96 } \\
\text { relA1 } \Delta(\text { laclZYA-argF }) \mathrm{U} 169 \text { deoR } \Phi_{80} \text { dlacZAM15 }\end{array}$ & Laboratory collection \\
\hline M15 & thi $\mathrm{lac}^{-} \mathrm{ara}^{+} \mathrm{gal}^{+} \mathrm{mtl}^{-} \mathrm{F}^{-} \mathrm{recA}^{+}$uvr lon $^{+} \mathrm{Nal}^{\mathrm{s}} \mathrm{Str}^{\mathrm{S}} \mathrm{Rif}^{\mathrm{S}}$ & Qiagen \\
\hline K5971 & MC4100 $\varphi($ proU-lacZ)hyb2 (גplac Mu15) zch-97::Tn 10 & Higgins et al. (1988) \\
\hline K5972 & 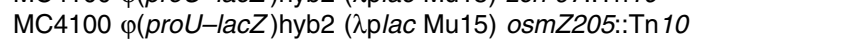 & Higgins et al. (1988) \\
\hline \multicolumn{3}{|l|}{ Plasmid } \\
\hline pLS716 & pBluescript SK $\pm ; p c t x A B ; A p^{R}$ & Li et al. (2000) \\
\hline pCS2.1 & pLARF2 with $t c p A:: p h o A$ insert; $\mathrm{Tc}^{\mathrm{R}} \mathrm{Km}^{\mathrm{R}}$ & Taylor et al. (1987) \\
\hline pQE30 & Expression vector with $6 \times$ His tag $5^{\prime}$ to the polylinker; $A p^{R}$ & Qiagen \\
\hline pREP4 & Low copy plasmid constitutively expresses lacl; $\mathrm{Km}^{\mathrm{R}}$ & Qiagen \\
\hline pQT8 & ORF of toxT cloned into pQE30 & This study \\
\hline pMMB208 & Cloning vector; $\mathrm{Cam}^{\mathrm{R}}$ & Morales et al. (1991) \\
\hline pMMTT & toxT cloned into pMMB208 & Higgins and DiRita (1994) \\
\hline pTL61T & lacZ transcriptional fusion vector; $\mathrm{Ap}^{\mathrm{R}}$ & Linn and Pierre (1990) \\
\hline pRY6 & -475 to +55 of $t c p A$ cloned into pTL61T & This study \\
\hline pRY7 & -285 to +55 of $t c p A$ cloned into pTL61T & This study \\
\hline pRY8 & -185 to +55 of $t c p A$ cloned into pTL61T & This study \\
\hline pRY9 & -135 to +55 of tcpA cloned into pTL61T & This study \\
\hline $\mathrm{pRY} 10$ & -85 to +55 of $t c p A$ cloned into pTL61T & This study \\
\hline pRY26 & -41 to +55 of $t c p A$ cloned into pTL61T & This study \\
\hline pRY27 & -21 to +55 of $t c p A$ cloned into pTL61T & This study \\
\hline pRY12 & -475 to -13 of $\operatorname{tcp} A$ cloned into PTL61T & This study \\
\hline $\mathrm{pRY} 13$ & -400 to +61 of $c t x$ cloned into pTL61T & This study \\
\hline pRY14 & -220 to +61 of $c t x$ cloned into pTL61T & This study \\
\hline pRY15 & -111 to +61 of $c t x$ cloned into pTL61T & This study \\
\hline pRY16 & -104 to +61 of $c t x$ cloned into pTL61T & This study \\
\hline pRY17 & -97 to +61 of $c t x$ cloned into pTL61T & This study \\
\hline pRY18 & -90 to +61 of $c t x$ cloned into pTL61T & This study \\
\hline pRY19 & -83 to +61 of $c t x$ cloned into pTL61T & This study \\
\hline pRY20 & -76 to +61 of $c t x$ cloned into pTL61T & This study \\
\hline pRY21 & -21 to +61 of $c t x$ cloned into pTL61T & This study \\
\hline pRY25 & -400 to -15 of $c t x$ cloned into pTL61T & This study \\
\hline pRY30 & -76 to -41 of $c t x$ fused to -40 to +55 of $t c p A$ and cloned into pTL61T & This study \\
\hline pTE103 & Promoterless transcription vector; $\mathrm{Ap}^{\mathrm{R}}$ & Elliott and Geiduscheck (1984) \\
\hline pRY28 & -220 to +61 of $c t x$ cloned into pTE103 & This study \\
\hline pRY29 & -285 to +55 of $t c p A$ cloned into pTE103 & This study \\
\hline
\end{tabular}

electrophoresis followed by gel extraction with the QIAEX II gel extraction system (Qiagen). Cloning was performed using standard protocols (Sambrook et al., 1989).

\section{Transcriptional fusion analysis}

PCR products harbouring various portions of the $c t x$ or $t c p A$ promoter region were generated with flanking HindIII and $X$ bal sites and subcloned into HindIII-Xbal-digested pTL61T. After the sequences were verified to be wild-type, plasmid DNA were transferred into $V$. cholerae or E. coli strains. Bacterial cells containing plasmids were grown overnight in LB medium at $37^{\circ} \mathrm{C}$, then subcultured $1: 50$ in fresh LB medium (with $1 \mathrm{mM}$ IPTG if necessary) and grown at $30^{\circ} \mathrm{C}$ for $3 \mathrm{~h}$.
Cells were harvested and $\beta$-galactosidase activity was measured as described (Miller, 1972).

\section{Purification of $6 \mathrm{H}$-ToxT}

A $6 \times$ histidine-tagged form of ToxT protein $(6 \mathrm{H}-\mathrm{ToxT})$ was constructed by fusing the histidine tag in frame to the $\mathrm{N}$ terminus of toxT open reading frame (ORF), under the control of a IPTG-inducible promoter (pQT8). Escherichia coli strain M15 harbouring both $\mathrm{pQT} 8$ and pREP4 was grown overnight in $\mathrm{LB}$ medium at $37^{\circ} \mathrm{C}$, then subcultured $1: 40$ in fresh LB medium and grown for $2 \mathrm{~h}$ at $37^{\circ} \mathrm{C}$ until $\mathrm{OD}_{600}$ was about 0.5 . $6 \mathrm{H}$-toxT expression was induced by adding IPTG to a final concentration of $1 \mathrm{mM}$, and the culture was grown continu- 
ously for $20 \mathrm{~h}$ at a temperature between $10^{\circ} \mathrm{C}$ and $12^{\circ} \mathrm{C}$. Bacterial cells were collected by centrifugation and cell pellets were freeze-thawed three times and resuspended in lysis buffer $\left(50 \mathrm{mM} \mathrm{NaH}{ }_{2} \mathrm{PO}_{4}, \mathrm{pH} 8.0 ; 300 \mathrm{mM} \mathrm{NaCl} ; 10 \mathrm{mM}\right.$ imidazole; $20 \mathrm{mM} \beta$-mercaptoethanol; $1 \mu \mathrm{M}$ leupeptin; $1 \mu \mathrm{M}$ pepstatin $\mathrm{A} ; 16.6 \mu \mathrm{M}$ PMSF). Lysozyme was added to a final concentration of $1 \mathrm{mgml}^{-1}$ to the bacterial suspension and incubated on ice for $30 \mathrm{~min}$. Cells were then sonicated six times on ice and centrifuged at $12000 \mathrm{~g}$ for $30 \mathrm{~min}$ at $4^{\circ} \mathrm{C}$. Supernatant was saved and $1 \mathrm{ml}$ of $50 \%$ Ni-NTA slurry (Qiagen) was added to every $4 \mathrm{ml}$ of the lysate. The mixture was gently mixed for at least $60 \mathrm{~min}$ at $4^{\circ} \mathrm{C}$ and then packed into a column. Column flow-through was collected and the beads were washed twice with $4 \mathrm{ml}$ of wash buffer ( $50 \mathrm{mM} \mathrm{NaH}_{2} \mathrm{PO}_{4}, \mathrm{pH} 8.0 ; 300 \mathrm{mM} \mathrm{NaCl} ; 20 \mathrm{mM}$ imidazole). $6 \mathrm{H}$-ToxT was eluted with five fractions of $0.5 \mathrm{ml}$ of elution buffer $\left(50 \mathrm{mM} \mathrm{NaH}_{2} \mathrm{PO}_{4}, \mathrm{pH} 8.0 ; 300 \mathrm{mM} \mathrm{NaCl}\right.$; $250 \mathrm{mM}$ imidazole). Samples collected were analysed by SDS-PAGE and fractions containing $6 \mathrm{H}$-ToxT were pooled and dialysed twice in dialysis buffer $\left(50 \mathrm{mM} \mathrm{NaH}_{2} \mathrm{PO}_{4} ; 10 \mathrm{mM}\right.$ Tris; $100 \mathrm{mM} \mathrm{NaCl}$; with a final $\mathrm{pH}$ of 6.5 ) at $4^{\circ} \mathrm{C}$. Protein concentration was determined using the Bio-Rad Protein Assay (Bio-Rad).

To ensure that $6 \mathrm{H}$-ToxT is active in vivo, the plasmid encoding $6 \mathrm{H}$-tox $T$ was transformed into both $E$. coli and $V$. cholerae strains carrying a $c t x-l a c Z$ fusion on the chromosome. In the $E$. coli background, there was a sevenfold induction of $\beta$-galactosidase activity when $6 \mathrm{H}$-ToxT was expressed, whereas in the $V$. cholerae background, there was a fivefold induction (data not shown). These data confirmed that the fusion protein is functional in vivo.

\section{Electrophoretic mobility shift assays (EMSAs)}

Plasmids containing the appropriate promoter fragments were first linearized with Notl (pLS716 for the ctx promoter) or BamHI (pRY8 for the tcpA promoter), then subjected to an end-labelling reaction containing a 2-mM mix of dATP, dGTP, and dTTP, $30 \mu \mathrm{Ci}$ of $\left[\alpha^{-32} \mathrm{P}\right]$-dCTP $\left(>3000 \mathrm{Ci} \mathrm{mmol}^{-1}\right.$, Amersham), and five units of Klenow (New England Biolabs). Reactions were incubated at room temperature for $8 \mathrm{~min}$, followed by $70^{\circ} \mathrm{C}$ for $15 \mathrm{~min}$. Samples were next digested with Sall (for the ctx promoter) or Hindlll (for the tcpA promoter) which cut the probe fragment out of the vector. Reactions were then electrophoresed on a $1 \times$ TBE, $6 \%$ polyacrylamide gel and subjected to autoradiography. Radiolabelled promoter fragments were excised out of the gel and eluted with elution buffer (0.5 M ammonium acetate, $\mathrm{pH} 7.5 ; 0.1 \%$ SDS; $1 \mathrm{mM}$ EDTA, pH 8.0) overnight at $30^{\circ} \mathrm{C}$. Samples were ethanol-precipitated, normalized to $20000 \mathrm{cpm} \mathrm{Il}^{-1}$, and used in electrophoretic mobility shift assays. Assays were performed in final volumes of $32 \mu \mathrm{l}$ with different concentrations of $6 \mathrm{H}$-ToxT, $10 \mu \mathrm{g} \mathrm{ml}^{-1}$ salmon sperm DNA, $20000 \mathrm{cpm}$ of probe in binding buffer with a final concentration of $10 \mathrm{mM}$ Tris, $\mathrm{pH}$ 7.5; $100 \mathrm{mM} \mathrm{KCl,} 1 \mathrm{mM}$ EDTA, pH 8.0; $1 \mathrm{mM}$ DTT; $10 \%$ glycerol and $0.3 \mathrm{mg} \mathrm{ml}^{-1}$ bovine serum albumin (BSA). The binding reactions were incubated at $30^{\circ} \mathrm{C}$ for $30 \mathrm{~min}$, then subjected immediately to electrophoresis on a $1 \times \mathrm{TBE}$, $6 \%$ polyacrylamide gel at $4^{\circ} \mathrm{C}$. Dried gels were analysed by autoradiography.

\section{DNase / footprinting}

Footprinting probes were generated by digesting pLS716 containing -181 to +7 of the ctx promoter region with either Notl (for labelling the top strand) or Sall (for labelling the bottom strand), and pRY8 containing -185 to +55 of the tcpA promoter region with $\mathrm{BamHI}$ (for labelling top strand) or HindIII (for labelling bottom strand), subjecting these samples to the end-labelling reaction described above, and digesting the probe fragment out of the vector with either Sall (for top $c t x$ strand), Notl (for bottom ctx strand), Hindlll (for top tcpA strand) or BamHI (for bottom tcpA strand). Probes were isolated and purified as described above. Binding reactions were performed as described above with the following modifications. Reactions were set up in final volumes of $112 \mu \mathrm{l}$ containing $70000 \mathrm{cpm}$ of probe and $175 \mu \mathrm{g}$ of BSA. After 30 min of binding at $30^{\circ} \mathrm{C}, \mathrm{CaCl}_{2}$ and $\mathrm{MgCl}_{2}$ were added to final concentrations of $1 \mathrm{mM}$ and $5 \mathrm{mM}$ respectively. Then, 0.01 units of DNase I (Roche) were added and incubated at room temperature for $2 \mathrm{~min}$. The reactions were stopped by the addition of an equal volume of stop buffer $(200 \mathrm{mM} \mathrm{NaCl}$; $2 \mathrm{mM}$ EDTA; $1 \%$ SDS), followed by two phenol-chloroform extractions. Nucleic acids were ethanol-precipitated and subjected to electrophoresis on a $1 \times \mathrm{TBE}, 6 \%$ polyacrylamide sequencing gel. To precisely map the position of the ToxT binding sites in the $c t x$ and $t c p A$ promoters, sequencing reactions were performed using T7 Sequenase Version 2.0 DNA sequencing kit (Amersham Life Sciences) on the appropriate strand in which the $5^{\prime}$-end of the sequencing primers corresponds to the $5^{\prime}$-end of the footprinting probes. The sequencing reactions were electrophoresed alongside the footprinting reactions.

\section{In vitro transcription}

Transcription reactions were performed in final volumes of $20 \mu$ l containing $50 \mathrm{nM}$ of supercoiled pRY28 or pRY29 template, $250 \mathrm{nM}$ of $6 \mathrm{H}$-ToxT, 10 units of RNase Inhibitor (Roche), in transcription buffer $(50 \mathrm{mM}$ Tris- $\mathrm{HCl}, \mathrm{pH} 8.0$; $3 \mathrm{mM}$ magnesium acetate, $0.1 \mathrm{mM}$ EDTA; $0.1 \mathrm{mM}$ DTT; $50 \mathrm{mM} \mathrm{NaCl} ; 25 \mu \mathrm{g}$ of nuclease-free BSA per ml). Reactions were first incubated at $30^{\circ} \mathrm{C}$ for 30 min without RNAP, then $1.29 \mathrm{nM} \sigma^{70}$-saturated $E$. coli RNA polymerase (Epicenter) was added to the tubes and initiation complexes were allowed to form by incubation at $30^{\circ} \mathrm{C}$ for $10 \mathrm{~min}$, followed by $37^{\circ} \mathrm{C}$ for $15 \mathrm{~min}$. A single round of transcription was initiated by addition of $2 \mu \mathrm{l}$ of a solution containing ATP, GTP and CTP at $5 \mathrm{mM}$ each, $0.5 \mathrm{mM}$ UTP, $2 \mu \mathrm{Ci}$ of $\left[\alpha^{-32} \mathrm{P}\right]-U T P(3000 \mathrm{Ci}$ $\mathrm{mmol}^{-1}$, Amersham), and $2 \mathrm{mg}$ of heparin per ml. After incubating at $37^{\circ} \mathrm{C}$ for $10 \mathrm{~min}$, reactions were stopped by the addition of $20 \mu \mathrm{l}$ of stop buffer $(0.55 \mathrm{M}$ sodium acetate, $\mathrm{pH} 7.0$; $30 \mathrm{mM}$ EDTA; $120 \mu \mathrm{g}$ of tRNA carrier per $\mathrm{ml}$ ). Samples were then extracted with phenol-chloroform and nucleic acids were precipitated by addition of ethanol, and subjected to electrophoresis on a $1 \times \mathrm{TBE}, 6 \%$ polyacrylamide sequencing gel. Dried gels were then analysed by autoradiography.

\section{Acknowledgements}

This work was supported by grant Al 31645 (to V.J.D.) and 
RR 00200 (to the Unit for Laboratory Animal Medicine, University of Michigan) from the National Institutes of Health. R.R.Y. is a trainee of the University of Michigan Genetics Training Grant (T32 GM 07544) and a recipient of the University of Michigan Rackham Predoctoral Fellowship.

We thank Alita Miller, Eric Krukonis and Jeff Withey for insightful comments on the manuscript. We also thank Stephen Winans and Carleen Collins for helpful discussion, and David Friedman for strains.

\section{References}

Afflerbach, H., Schröder, O., and Wagner, R. (1999) Conformational changes of the upstream DNA mediated by $\mathrm{H}-\mathrm{NS}$ and FIS regulate $E$. coli $r \mathrm{rnB}_{\mathrm{P} 1}$ promoter activity. $J \mathrm{Mol}$ Biol 286: 339-353.

Atlung, T., and Ingmer, H. (1997) H-NS: a modulator of environmentally regulated gene expression. Mol Microbiol 24: 7-17.

Atlung, T., Sund, S., Olesen, K., and Brøndsted, L. (1996) The histone-like protein $\mathrm{H}-\mathrm{NS}$ acts as a transcriptional repressor for expression of the anaerobic and growth phase activator AppY of Escherichia Coli. J Bacteriol 178: 3418-3425.

Betley, M.J., Miller, V.L., and Mekalanos, J.J. (1986) Genetics of bacterial enterotoxins. Annu Rev Microbiol 40: 577-605.

Bhende, P.M., and Egan, S.M. (2000) Genetic evidence that transcription activation by RhaS involves specific amino acid contacts with sigma 70. J Bacteriol 182: 49594969.

Blomfield, I.C., McClain, M.S., and Eisenstein, B.I. (1991) Type 1 fimbriae mutants of Escherichia coli K12: characterization of recognized afimbriate strains and construction of new fim deletion mutants. Mol Microbiol 5: 14391445.

Brown, R.C., and Taylor, R.K. (1995) Organization of the tcp, acf and toxT genes within a ToxT-dependent operon. Mol Microbiol 16: 425-439.

Busby, S., and Ebright, R.H. (1997) Transcription activation at class II CAP-dependent promoters. Mol Microbiol 23: 853-859.

Busby, S., and Ebright, R.H. (1999) Transcription activation by catabolite activator protein (CAP). J Mol Biol 293: 199-213.

Champion, G.A., Neely, M.N., Brennan, M.A., and DiRita, V.J. (1997) A branch in the ToxR regulatory cascade of Vibrio cholerae revealed by characterization of tox $T$ mutant strains. Mol Microbiol 23: 323-331.

Coker, C., Bakare, O.O., and Mobley, H.L.T. (2000) H-NS is a repressor of the Proteus mirabilis urease transcriptional activator gene ureR. J Bacteriol 182: 2649-2653.

Dhiman, A., and Schleif, R. (2000) Recognition of overlapping nucleotides by $\mathrm{AraC}$ and the sigma subunit of RNA polymerase. J Bacteriol 182: 5076-5081.

Diekmann, S. (1986) Sequence specificity of curved DNA. FEBS Lett 195: 53-56.

DiRita, V.J., Parsot, C., Jander, G., and Mekalanos, J.J. (1991) Regulatory cascade controls virulence in Vibrio Cholerae. Proc Natl Acad Sci USA 88: 5403-5407.
Ebright, R.H. (1993) Transcription activation at class I CAPdependent promoters. Mol Microbiol 8: 797-802.

Egan, S.M., Pease, A.J., Lang, J., Li, X., Rao, V., Gillette, W.K., et al. (2000) Transcription activation by a variety of AraC/XylS family activators does not depend on the class II-specific activation determinant in the N-terminal domain of the RNA polymerase alpha subunit. $J$ Bacteriol 182: 7075-7077.

Elliott, T., and Geiduscheck, E.P. (1984) Defining a bacteriophage T4 late promoter: absence of a '-35' region. Cell 36: 211-219.

Fawcett, W.P., and Wolf, R.E., Jr. (1995) Genetic definition of the Escherichia coli zwf 'soxbox', the DNA binding site for SoxS-mediated induction of glucose 6-phosphate dehydrogenase in response to superoxide. J Bacteriol 177: 1742-1750.

Finkelstein, R.A. (1973) Cholera. CRC Crit Rev Microbiol 2: 553-623.

Gallegos, M.-T., Schleif, R., Bairoch, A., Hofmann, K., and Ramos, J.L. (1997) AraC/XylS family of transcriptional regulators. Microbiol Mol Biol Rev 61: 393-410.

Gardel, C.L., and Mekalanos, J.J. (1994) Regulation of cholera toxin by temperature, $\mathrm{pH}$, and osmolarity. Methods Enzymol 235: 517-526.

Gill, D.M. (1976) The arrangement of subunits in cholera toxin. Infect Immun 52: 1242-1248.

Gupta, S., and Chowdhury, R. (1997) Bile affects production of virulence factors and motility of Vibrio Cholerae. Infect Immun 65: 1131-1134.

Häse, C.C., and Mekalanos, J.J. (1998) TcpP protein is a positive regulator of virulence gene expression in Vibrio Cholerae. Proc Natl Acad Sci USA 95: 730-734.

Higgins, D.E., and DiRita, V.J. (1994) Transcriptional control of toxT, a regulatory gene in the ToxR regulon of Vibrio cholerae. Mol Microbiol 14: 17-29.

Higgins, C.F., Dorman, C.J., Stirling, D.A., Waddell, L., Booth, I.R., May, G., and Bremer, E. (1988) A physiological role for DNA supercoiling in the osmotic regulation of gene expression in S. typhimurium and E. coli. Cell 52: 569-584.

Higgins, D.E., Nazareno, E., and DiRita, V.J. (1992) The virulence gene activator ToxT from Vibrio cholerae is a member of the AraC family of transcriptional activators. $J$ Bacteriol 174: 6974-6980.

Jair, K.-W., Martin, R.G., Rosner, J.L., Fujita, N., Ishihama, A., and Wolf, R.E. Jr (1995) Purification and regulatory properties of MarA protein, a transcriptional activator of Escherichia coli multiple antibiotic and superoxide resistance promoters. J Bacteriol 177: 7100-7104.

Jair, K.-W., Fawcett, W.P., Fujita, N., Ishihama, A., and Wolf, R.E. Jr (1996a) Ambidextrous transcriptional activation by SoxS: requirement for the C-terminal domain of the RNA polymerase alpha subunit in a subset of Escherichia coli superoxide-inducible genes. Mol Microbiol 19: 307-317.

Jair, K.-W., Yu, X., Skarstad, K., Thony, B., Fujita, N., Ishihama, A., and Wolf, R.E., Jr. (1996b) Transcriptional activation of promoters of the superoxide and multiple antibiotic resistance regulons by Rob, a binding protein of the Escherichia coli origin of chromosomal replication. $J$ Bacteriol 178: 2507-2513.

Jordi, B.J.A.M., Dagberg, B., de Haan, L.A.M., Hamers, A.M., van der Zeijst, B.A.M., Gaastra, W., and Uhlin, B.E. (1992) 
The positive regulator $\mathrm{CfaD}$ overcomes the repression mediated by histone-like protein $\mathrm{H}-\mathrm{NS}(\mathrm{H} 1)$ in the CFA/I fimbrial operon of Escherichia coli. EMBO J 11: 2627-2632.

Kaldalu, N., Mandel, T., and Ustav, M. (1996) TOL plasmid transcription factor XylS binds specifically to the $P_{M}$ operator sequence. Mol Microbiol 20: 569-579.

Karaolis, D.K., Johnson, J.A., Bailey, C.C., Boedeker, E.C., Kaper, J.B., and Reeves, P.R. (1998) A Vibrio cholerae pathogenicity island associated with epidemic and pandemic strains. Proc Natl Acad Sci USA 95: 31343139.

Kaufman, M.R., Shaw, C.E., Jones, I.D., and Taylor, R.K. (1993) Biogenesis and regulation of the Vibrio cholerae toxin-coregulated pilus: analogies to other virulence factor secretory systems. Gene 126: 43-49.

Kolb, A., Busby, S., Buc, H., Garges, S., and Adhya, S. (1993) Transcriptional regulation by cAMP and its receptor protein. Annu Rev Biochem 62: 749-795.

Koo, H.-S., Wu, H.-M., and Crothers, D.M. (1986) DNA bending at adenine: thymine tracts. Nature 320: 501-506.

Krukonis, E.S., Yu, R.R., and DiRita, V.J. (2000) The Vibrio cholerae ToxR/TcpP/ToxT virulence cascade: distinct roles for two membrane-localized transcriptional activators on a single promoter. Mol Microbiol 38: 67-84.

Landini, P., and Busby, S.J.W. (1999) The Escherichia coli Ada protein can interact with two distinct determinants in the $\mathrm{s}^{70}$ subunit of RNA polymerase according to promoter architecture: identification of the target of Ada activation at the alkA promoter. J Bacteriol 181: 1524-1529.

Lee, S.H., Hava, D.L., Waldor, M.K., and Camilli, A. (1999) Regulation and temporal expression patterns of Vibrio cholerae virulence genes during infection. Cell 99: 625-634.

Li, C.C., Crawford, J.A., DiRita, V.J., and Kaper, J.B. (2000) Molecular cloning and transcriptional regulation of ompT, a ToxR-repressed gene in Vibrio Cholerae. Mol Microbiol 35: 189-203.

Linn, T., and Pierre, R.S. (1990) Improved vector system for constructing transcriptional fusions that ensure independent translation of lacZ. J Bacteriol 172: 1077-1084.

Martin, R.G., Gillette, W.K., Rhee, S., and Rosner, J.L. (1999) Structural requirements for marbox function in transcriptional activation of mar/sox/rob regulon promoters in Escherichia coli: sequence, orientation and spatial relationship to the core promoter. Mol Microbiol 34: 431441.

Miller, J.H. (1972) Experiments in Molecular Genetics. Cold Spring Harbor, NY: Cold Spring Harbor Laboratory Press.

Miller, V.L., and Mekalanos, J.J. (1984) Synthesis of cholera toxin is positively regulated at the transcriptional level by ToxR. Proc Natl Acad Sci USA 81: 3471-3475.

Miller, V.L., and Mekalanos, J.J. (1988) A novel suicide vector and its use in construction of insertion mutations: osmoregulation of outer membrane proteins and virulence determinants in Vibrio cholerae requires tox $R$. J Bacteriol 170: 2575-2583.

Morales, V.M., Backman, A., and Bagdasarian, M. (1991) A series of wide-host-range low-copy-number vectors that allow direct screening for recombinants. Gene 97: 39-47. Munson, G.P., and Scott, J.R. (1999) Binding site recognition by Rns, a virulence regulator in the AraC family. $J$ Bacteriol 181: 2110-2117.

Murphree, D., Froehlich, B., and Scott, J.R. (1997) Transcriptional control of genes encoding CS1 pili: negative regulation by a silencer and positive regulation by Rns. $J$ Bacteriol 179: 5736-5743.

Nye, M.B., Pfau, J.D., Skorupski, K., and Taylor, R.K. (2000) Vibrio cholerae $\mathrm{H}-\mathrm{NS}$ silences virulence gene expression at multiple steps in the ToxR regulatory cascade. J Bacteriol 182: 4295-4303.

Ogierman, M.A., Zabihi, S., Mourtzios, L., and Manning, P.A. (1993) Genetic organization and sequence of the promoter-distal region of the tcp gene cluster of Vibrio Cholerae. Gene 126: 51-60.

Parkinson, G., Wilson, C., Gunasekera, A., Ebright, Y., Ebright, R., and Berman, H. (1996) Structure of the CAPDNA complex at 2.5Å resolution. J Mol Biol 260: 395-408.

Pearson, G.D., and Mekalanos, J.J. (1982) Molecular cloning of Vibrio cholerae enterotoxin genes in Escherichia coli K-12. Proc Natl Acad Sci USA 79: 2976-2980.

Pérez-Martín, J., de Rojo, F., and Lorenzo, V. (1994) Promoters responsive to DNA bending: a common theme in prokaryotic gene expression. Microbiol Rev 58: 268-290.

Peterson, K.M., and Mekalanos, J.J. (1988) Characterization of the Vibrio cholerae ToxR regulon: identification of novel genes involved in intestinal colonization [published erratum appears in Infect Immun 1989, February; 57 (2): 660]. Infect Immun 56: 2822-2829.

Pfau, J.D., and Taylor, R.K. (1996) Genetic footprint of the ToxR-binding site in the promoter for cholera toxin. Mol Microbiol 20: 213-222.

Reeder, T., and Schleif, R. (1993) AraC protein can activate transcription from only one position and when pointed in only one direction. J Mol Biol 231: 205-218.

Rhee, S., Martin, R.G., Rosner, J.L., and Davies, D.R. (1998) A novel DNA-binding motif in MarA: the first structure for an AraC family transcriptional activator. Proc Natl Acad Sci USA 95: 10413-10418.

Rimsky, S., and Spassky, A. (1990) Sequence determinants for $\mathrm{H} 1$ binding on Escherichia coli lac and gal promoters. Biochemistry 29: 3765-3771.

Sambrook, J., Fritsch, E.F., and Maniatis, T. (1989). Molecular Cloning: a Laboratory Manual. Cold Spring Harbor, NY: Cold Spring Harbor Laboratory Press.

Schuhmacher, D.A., and Klose, K.E. (1999) Environmental signals modulate ToxT-dependent virulence factor expression in Vibrio Cholerae. J Bacteriol 181: 1508-1514.

Schultz, S., Shields, G., and Steitz, T. (1991) Crystal structure of a CAP-DNA complex: the DNA is bent by $90^{\circ}$. Science 253: 1001-1007.

Skorupski, K., and Taylor, R.K. (1997) Control of the ToxR virulence regulon in Vibrio cholerae by environmental stimuli. Mol Microbiol 25: 1003-1009.

Taylor, R.K., Miller, V.L., Furlong, D.B., and Mekalanos, J.J. (1987) Use of phoA gene fusions to identify a pilus colonization factor coordinately regulated with cholera toxin. Proc Natl Acad Sci USA 84: 2833-2837.

Thomas, V.J., and Collins, C.M. (1999) Identification of UreR binding sites in the Enterobacteriaceae plasmid-encoded and Proteus mirabilis urease gene operons. Mol Microbiol 31: 1417-1428. 
Tobe, T., Yoshikawa, M., Mizuno, T., and Sasakawa, C. (1993) Transcriptional control of the invasion regulatory gene virB of Shigella flexneri: activation by VirF and repression by H-NS. J Bacteriol 175: 6142-6149.

Wattiau, P., and Cornelis, G.R. (1994) Identification of DNA sequences recognized by VirF, the transcriptional activator of the Yersinia yop regulon. $J$ Bacteriol 176: 3878-3884.
Williams, R.M., and Rimsky, S. (1997) Molecular aspects of the $E$. coli nucleoid protein, H-NS: a central controller of gene regulatory networks. FEMS Microbiol Lett 156: 175-185.

Yu, R.R., and DiRita, V.J. (1999) Analysis of an autoregulatory loop controlling ToxT, cholera toxin, and toxincoregulated pilus production in Vibrio cholerae. J Bacteriol 181: 2584-2592. 